\title{
Phototransduction and retinal degeneration in Drosophila
}

\author{
Tao Wang • Craig Montell
}

Received: 24 January 2007 / Accepted: 5 March 2007 / Published online: 9 May 2007

(C) Springer-Verlag 2007

\begin{abstract}
Drosophila visual transduction is the fastest known G-protein-coupled signaling cascade and has therefore served as a genetically tractable animal model for characterizing rapid responses to sensory stimulation. Mutations in over 30 genes have been identified, which affect activation, adaptation, or termination of the photoresponse. Based on analyses of these genes, a model for phototransduction has emerged, which involves phosphoinoside signaling and culminates with opening of the TRP and TRPL cation channels. Many of the proteins that function in phototransduction are coupled to the PDZ containing scaffold protein INAD and form a supramolecular signaling complex, the signalplex. Arrestin, TRPL, and $\mathrm{G} \alpha_{\mathrm{q}}$ undergo dynamic light-dependent trafficking, and these movements function in long-term adaptation. Other proteins play important roles either in the formation or maturation of rhodopsin, or in regeneration of phosphatidylinositol 4,5bisphosphate $\left(\mathrm{PIP}_{2}\right)$, which is required for the photoresponse. Mutation of nearly any gene that functions in the photoresponse results in retinal degeneration. The underlying bases of photoreceptor cell death are diverse and involve mechanisms such as excessive endocytosis of rhodopsin due to stable rhodopsin/arrestin complexes and abnormally low or high levels of $\mathrm{Ca}^{2+}$. Drosophila visual transduction appears to have particular relevance to the cascade in the
\end{abstract}

T. Wang $\cdot$ C. Montell $(\triangle)$

Department of Biological Chemistry, Center for Sensory Biology,

The Johns Hopkins University School of Medicine,

Baltimore, MD 21205, USA

e-mail: cmontell@jhmi.edu

T. Wang $\cdot$ C. Montell

Department of Neuroscience, Center for Sensory Biology,

The Johns Hopkins University School of Medicine,

Baltimore, MD 21205, USA intrinsically photosensitive retinal ganglion cells in mammals, as the photoresponse in these latter cells appears to operate through a remarkably similar mechanism.

Keywords Drosophila $\cdot$ Phototransduction .

Retinal degeneration

\section{Introduction}

Overview and relationship of Drosophila to mammalian phototransduction

Drosophila vision is the first sensory modality to be subjected to detailed genetic analyses in any animal [1]. The appeal of this system stems in part from the observation that it functions through the fastest known Gprotein-coupled signaling cascade as it is maximally activated in as little as 20 milliseconds [2]. As such it provides a model for characterizing the mechanisms underlying rapid responses to sensory stimulation.

Drosophila phototransduction offers the opportunity to combine classical and modern genetic approaches to identify genes and proteins that function in phototransduction using electrophysiological, cell biological, and biochemical approaches. This latter advantage, the ease of performing biochemical assays, is a consequence of the architecture of the fly's compound eye each of which is comprised of a reiteration of $\sim 800$ simple eyes. Consequently, all the photoreceptor cell proteins are expressed in many cells, greatly reducing a problem inherent in many signaling systems, the low abundance of the essential proteins, and signaling molecules. Not least among the tools that have driven the progress of Drosophila phototransduction are electroretinogram recordings (ERGs), an 
electrophysiological assay that is so simple that it can be used to perform large-scale genetic screens as pioneered by Pak and colleagues [3]. Once mutations are isolated, the bases of the defects can be assessed in greater detail by applying additional electrophysiological approaches, including intracellular recordings and patch clamp analyses [2, 4].

During the 40 years that have elapsed since the initial studies on Drosophila visual transduction, many of the mysteries underlying the cascade have been unraveled. These include the demonstration that the cascade operates through activation of a phospholipase C $\beta$ (PLC) [5] and opening of the TRP and TRPL cation channels [6-9] (Fig. 1). These insights led to a puzzle, and later to an exciting surprise, concerning the parallels between Drosophila and mammalian phototransduction. While the cascades in vertebrate rods and cones, and fly photoreceptor cells are both initiated by activation of related rhodopsins and engagement of heterotrimeric G-proteins, there are notable differences. In contrast to fly photoreceptor cells, light stimulation of the rhodopsins in rods and cones leads to an increase in the activity of a cyclic guanosine monophosphate (cGMP) phosphodiesterase, a subsequent drop in cGMP levels, and closure of the cGMP-gated channels [10]. Thus, the effects of light stimulation on the channels are opposite in fly photoreceptor cells compared to rods and cones.

Therefore, what is the relationship between vertebrate and invertebrate phototransduction? Did they evolve separately? During the last few years, it has become clear that there is a small subset of retinal ganglion cells that are intrinsically photosensitive (ipRGCs), and which function in photoentrainment of circadian rhythm and in light-induced pupillary constriction [11]. Moreover, it appears that the phototransduction cascade in the ipRGCs bears striking similarities to that in fly photoreceptors. The cascade in the ipRGCs is initiated through a receptor, melanopsin, which has greater sequence and biophysical similarities to the Drosophila rhodopsins [12-18] than the light receptors in rods and cones. Furthermore, pharmacological and electrophysiological studies suggest that the ipRGC cascade functions through a PLC and opening of channels that display features reminiscent of TRP channels [19-21]. Although, most of the specific signaling proteins in the ipRGCs remain to be identified, it appears that the Drosophila and mammalian ipRGC phototransduction cascades share common origins.

\section{The Drosophila compound eye}

The Drosophila compound eye is comprised of $\sim 800$ hexagonal units, ommatidia (Fig. 2a), each of which contains 20 cells including eight photoreceptor cells. Six of the photoreceptor cells (R1-6) extend the full depth of the retina $(\sim 85 \mu \mathrm{m})$, while the remaining two (R7 and $\mathrm{R} 8$ ) occupy the distal and proximal regions of the ommatidia, respectively (Fig. $2 \mathrm{c}$ and d). The main cells surrounding the photoreceptor cells are secondary pigment cells. The vertices of the ommatidia alternate between tertiary pigment cells and mechanosensory bristle cells (Fig. 2d).

Each photoreceptor cell contains a microvillar structure, referred to as the rhabdomere, which is the functional equivalent of the rod and cone outer segment (Fig. 2e and f). The $\sim 50,000$ and 17,000 microvilli in the R1-6 and R7/8 cells, respectively, provide a massive plasma membrane surface to pack in a high concentration of rhodopsin and is also the site for most of the proteins that function in phototransduction. Due to a curvature of the eye (Fig. 2b), the diameter of the R1-6 cell rhabdomeres is nearly $2 \mu \mathrm{m}$ near the distal region and narrows to just over $1 \mu \mathrm{m}$ at the proximal end. The R7/8 rhabdomeral diameters are even smaller and are just slightly more than half that of the larger R1-6 cells.

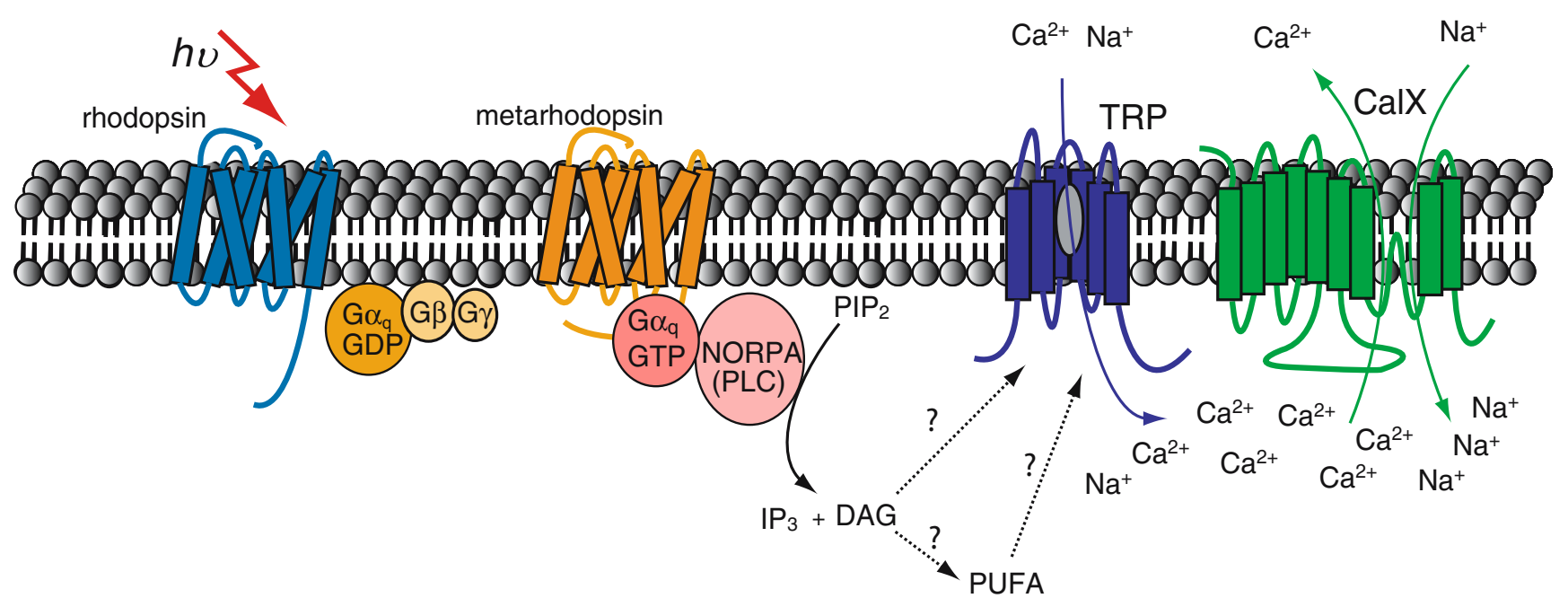

Fig. 1 Model of the Drosophila phototransduction cascade. See the text for details 
Fig. 2 Structure of the Drosophila compound eye. a Scanning EM of a compound eye. b Section through adult fly head: $b r$, brain; $f b$, fat bodies; la, lamina; lo, lobula; $l p$, lobula plate; me, medulla; re, retina. c Single ommatidium at an angle $90^{\circ}$ from the surface of the compound eye: co, cornea; primary $P C$, primary pigment cell; psC, pseudocone; secondary $P C$, secondary pigment cell; $R 1-6$, photoreceptor cells $1-6$; $R 7$, photoreceptor cell 7; $R 8$, photoreceptor cell 8. d Crosssections through the distal and proximal regions of the ommatidia. Seven photoreceptor cells are present in any given plane of section. The ovals represent the rhabdomeres. The $\mathrm{R}$ cell bodies are numbered. A secondary pigment cell, a tertiary pigment cell and a mechanosensory bristle cell are indicated.

e Longitudinal view through a photoreceptor cell. The rhabdomere, axon, and nucleus $(N)$ are indicated. f Cross-sectional view through a photoreceptor cell.

The approximate average dimensions of an R1- 6 cell microvillus are indicated
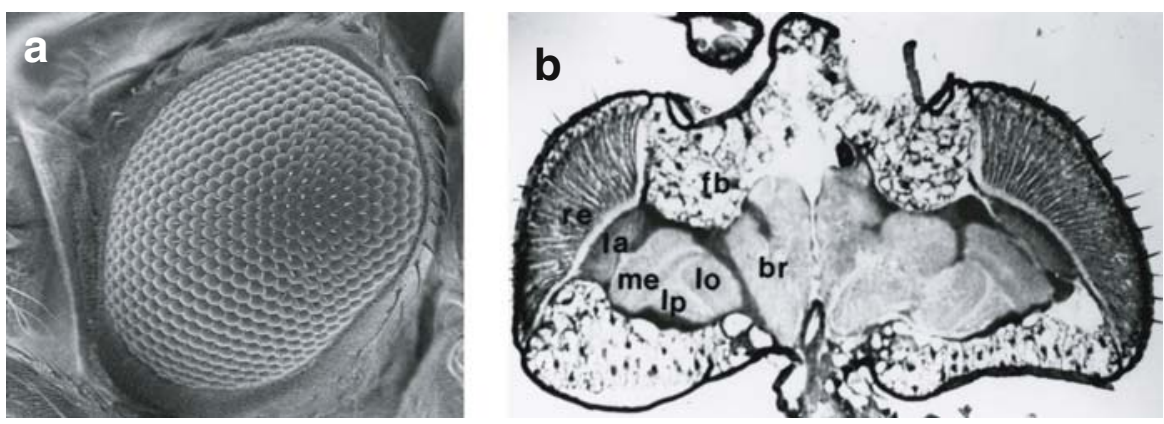

C

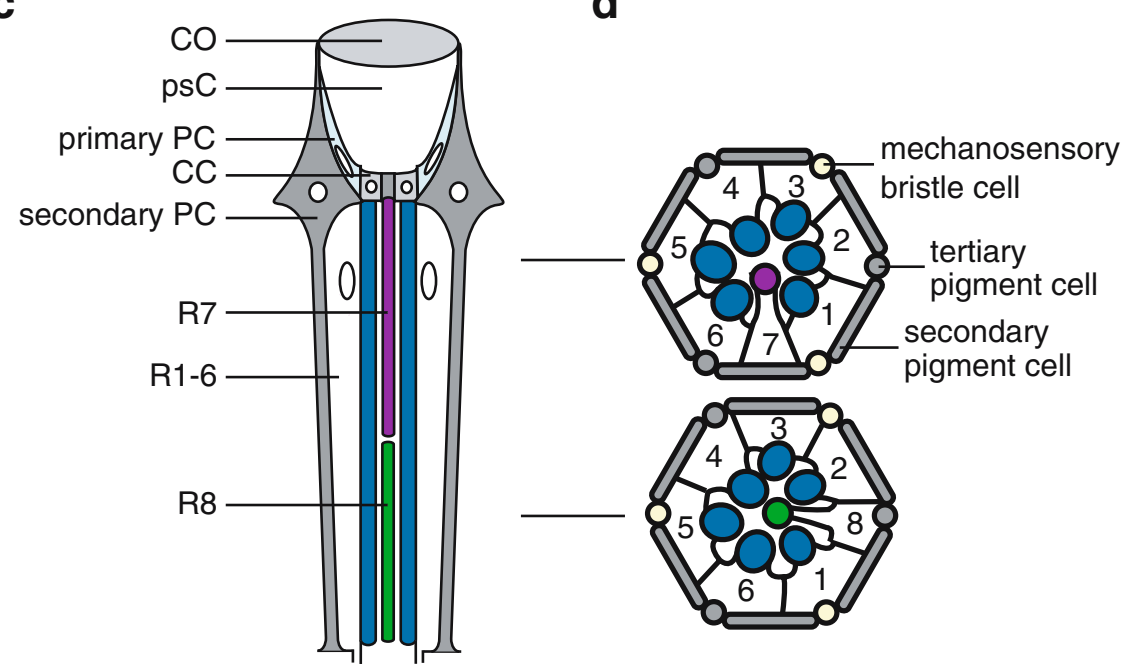

e

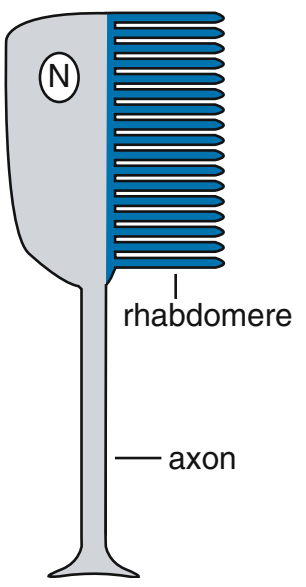

f

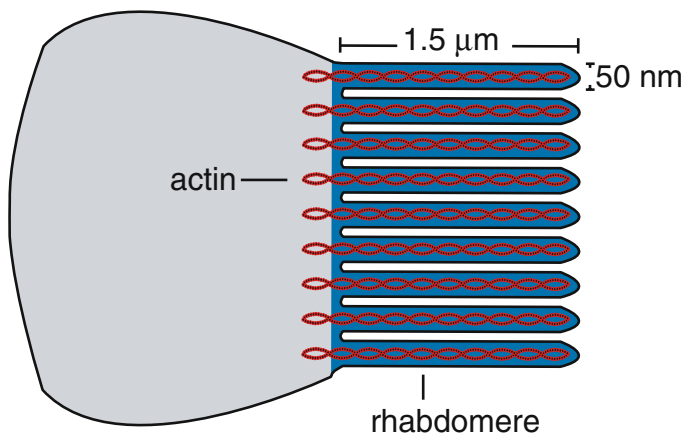

The dimensions of each microvillus are quite small - they are only $50 \mathrm{~nm}$ wide and the space within the rhabdomeral cell bodies is limited further by the presence of an actin filament extending into the extra-rhabdomeral cell bodies (Fig. 2f). A single myosin III appears to span the small distance between the actin filament and the rhabdomeral membrane [22, 23]. The extremely small size of a microvillus has important implications concerning the mechanism of signal amplifica- tion. According to one model, the extent of amplification by a photon of light is defined by the number of signaling molecules in a single microvillus [24-26].

Genetic approaches to Drosophila phototransduction

Since the compound eye is not required for viability, it is feasible to screen for mutations affecting the visual response 
in adult flies. Some of the early genetic approaches relied on behavioral assays such as phototaxis or changes in body orientation in response to moving visual cues (the optomotor response; reviewed in [27]). Mutations affecting phototransduction have also been isolated by examining flies for evidence of retinal degeneration [28-30].

The most sensitive and productive screen for genes required for phototransduction relied on a simple electrophysiological test, the ERG recording [3]. ERGs are extracellular recordings, which measure the summed responses of all the retinal cells to light, and are typically performed with white light by placing a recording electrode on the surface of the compound eye. There are two primary features of the ERG, the maintained component (or light coincident receptor potential; LCRP) that results from the activity in the retina, and the on- and off-transients (Fig. 3a), which occur due to activity postsynaptic to the photoreceptor cells in the lamina (Fig. 2b). Mutations that affect the LCRP occur due to defects either in activation, adaptation, or termination of the photoresponse (Fig. 3b-e) and are considered in the current review.

A variation of the standard ERG paradigm has led to the identification of many mutations affecting the major rhodop$\sin , \mathrm{Rh} 1$. Exposure of flies to blue $(480 \mathrm{~nm})$ light locks Rh1 in an activated metarhodopsin state. Therefore, upon termination of the light stimulus, there is a prolonged depolarization afterpotential (PDA; Fig. 3f). Termination of the PDA is achieved by orange (580) or white light, which triggers the conversion of the metarhodopsin back to the nonactivated rhodopsin (Fig. 3f). Mutations that reduce the PDA (Fig. 3g) affect either the synthesis, maturation, transport, or activity of the opsin or the chromophore.

The forward genetic screens for mutations affecting the photoresponse have lead to the identification of many genes required for phototransduction (Table 1). However, the screens have not been carried to saturation. Therefore, as a complementary approach, a growing number of candidate genes, based on studies of mammalian phototransduction, have been disrupted using reverse genetic approaches. An alternative unbiased strategy to identify candidate phototransduction genes takes advantage of the observation that nearly all of the genes known to function in the visual response are expressed primarily in the eye. Using DNA microarrays, nearly 100 previously uncharacterized "eyeenriched" genes were identified (eye-enrichment from 2- to 500-fold) [31], two of which have been mutated and shown to function in the visual response [31-33].

Characterization of the $>30$ genes, which were identified using either forward or reverse genetic approaches (Table 1), has led to a formulation of a model for Drosophila phototransduction, as well as insights into a variety of highly related questions. These include the biosynthesis of the opsin and chromophore, the mechanisms and function of light-dependent movements of signaling proteins, and the organization of a supramolecular complex comprising many of the proteins functioning in phototransduction. Of particular importance are the many advances concerning the mechanisms underlying the retinal degeneration that results from mutations in genes required for the visual response. Despite the differences between the cascades in Drosophila photoreceptor cells and rods and cones, there appear to be important parallels between the mechanisms underlying Drosophila retinal degeneration and human retinal dystrophies.

\section{The light receptors: rhodopsins}

The rhodopsins in both Drosophila and vertebrate photoreceptor cells are related molecules comprised of two types of subunits. These include a seven transmembrane protein, referred to as the opsin and a chromophore, which is covalently linked to a lysine residue in the seventh transmembrane domain through a Schiff base linkage. In vertebrates the chromophore is 11-cis retinal, while in Drosophila it is the highly related derivative, 11-cis 3hydroxyretinal [34-36]. Light absorption results in isomerization of the 11-cis retinal to form all-trans retinal, which initiates a conformational change in the opsin. Metarhodopsin, the active form of rhodopsin, in turn activates heterotrimeric G-proteins [37-39]. In rods and cones light stimulation leads to dissociation of the all-trans retinal from the opsin through breakage of the Schiff base linkage. The rhodopsin is subsequently regenerated through recombination of the 11-cis retinal and opsin. In Drosophila photoreceptor cells the major Rh1 metarhodopsin is stable since the chromophore does not dissociate. Rather, regeneration of rhodopsin requires exposure to a second photon of white or orange light (Fig. 4). Consequently, a PDA is produced upon termination of a blue light stimulus (Fig. 3f). A similar two photon visual cycle may also exist in the ipRGCs in mammals [11].

\section{Diversity of Drosophila rhodopsins}

At least six rhodopsins are expressed in Drosophila, each of which displays a distinct spectral sensitivity and expression pattern (Table 2). The predominant Drosophila rhodopsin, $\mathrm{Rh} 1$, encoded by the ninaE (neither inactivation nor afterpotential $E$ ) gene is the only rhodopsin expressed in the R1-R6 photoreceptor cells [40, 41]. The minor opsins expressed in the central R7 and R8 photoreceptor cells are coordinately expressed in nonoverlapping subsets of cells. $\mathrm{Rh} 3$ and $\mathrm{Rh} 4$ are ultraviolet-absorbing visual pigments expressed in $\sim 30$ and $70 \%$ of the R7 cells respectively in a seemingly randomly pattern of distribution [42-45]. As 
Fig. 3 ERG recordings from wild-type and representative mutants. a-e ERGs performed on wild-type and the indicated mutants using orange light. Amplitude $(m V)$ and time-scale $(s)$ markers are included. The event markers below the ERGs indicate the initiation and cessation of the light stimuli. The on- and off-transients and the maintained component $(m c)$ are indicated. $\mathbf{f}, \mathbf{g}$ The indicated strains of flies were exposed to multiple pulses of orange $(O, 580 \mathrm{~nm})$ and blue $(B, 480 \mathrm{~nm})$ light. The prolonged depolarization afterpotential $(P D A)$ is indicated

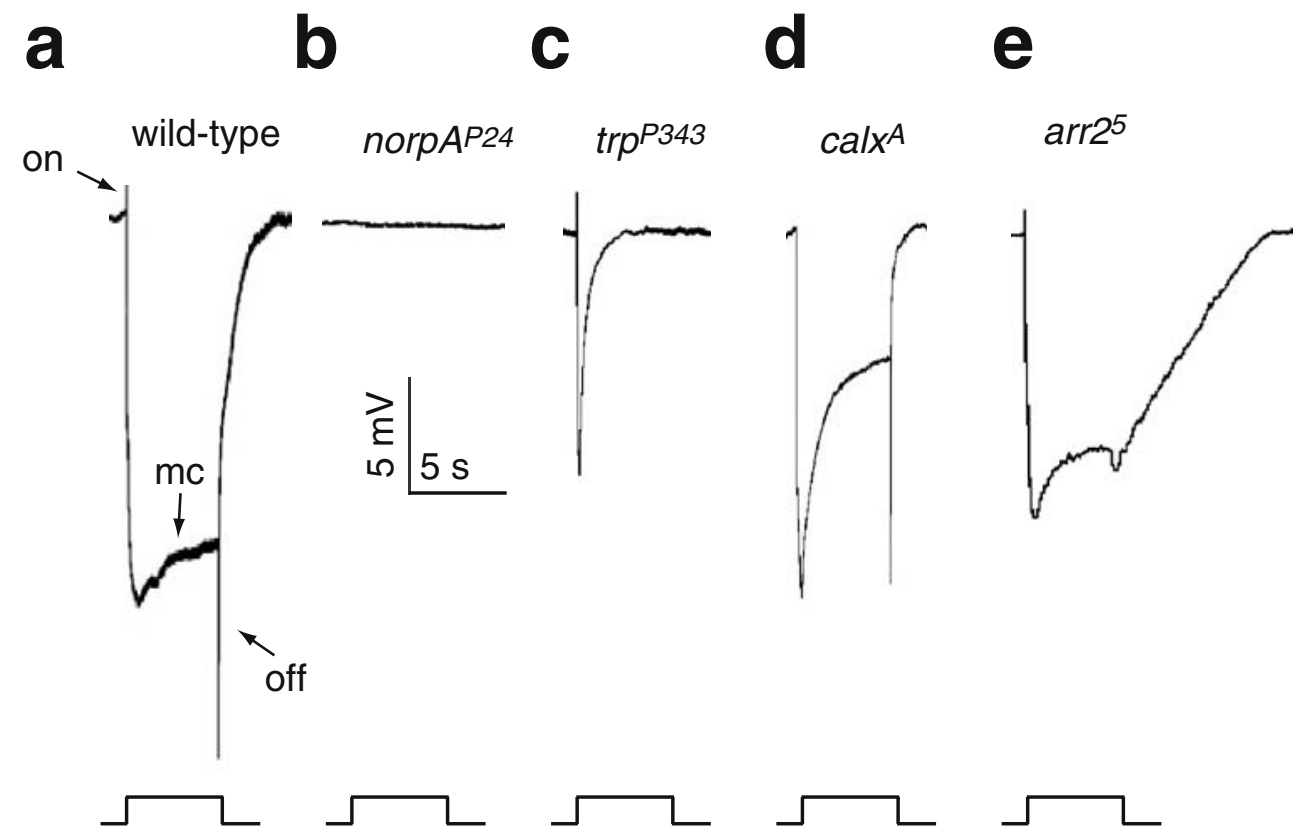

f

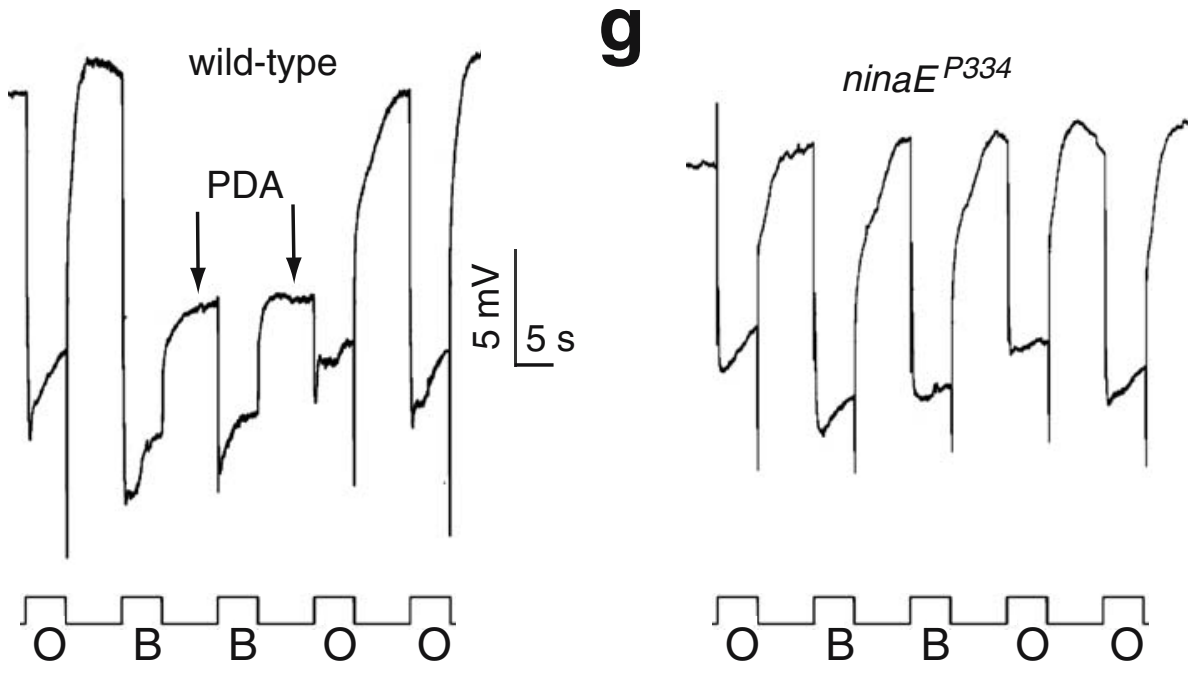

with the R7 cells, the same relative proportions of $\mathrm{R} 8$ cells, 30 and $70 \%$, express the blue (Rh5) and green (Rh6) absorbing pigments, respectively [46-48].

Every Rh3 expressing R7 cell is situated in the same ommatidium as the Rh5 expressing R8, while expression of $\mathrm{Rh} 4$ and Rh6 are coupled in the remaining ommatidia [46, 47, 49]. The different sets of Rh3/Rh5 and Rh4/Rh6 expressing $\mathrm{R} 7 / \mathrm{R} 8$ cells appear to correspond to the previously described pairs of $7 y / 8 y$ and $7 p / 8 p$ photoreceptor cells of the housefly, so-named based on their yellow or pale appearance in transmitted light [50]. The coordinate expression of the two pairs of R7 and R8 rhodopsins may contribute to spectral tuning due to the presence of a screening pigment in the Rh4 expressing R7 cells, which filters the light before it stimulates Rh6 in the R8 cells [51, 52]. In contrast to most ommatidia, the dorsal margin of the compound eye contains ommatidia that express $\mathrm{Rh} 3$ in both the R7 and R8 cells [45]. A violet-absorbing rhodopsin, $\mathrm{Rh} 2$, is expressed exclusively in the photoreceptor cells of the three ocelli, the simpler eyes localized on the vertex of the fly head [53-56].

\section{Maturation of rhodopsin}

Rh1 is synthesized in the endoplasmic reticulum (ER) and transported to the rhabdomere via the secretory pathway. The translocation of Rh1 from the ER to the rhabdomere depends on a protein related to peptidyl-prolyl cis-trans 
Table 1 Genes required for a normal visual response

\begin{tabular}{|c|c|c|c|}
\hline Gene & Identification method & Molecular function & ERG phenotype \\
\hline arrl & Western blot screen & Minor arrestin & Enhances arr2 phenotype \\
\hline arr 2 & Western blot screen & Major arrestin & Slow termination \\
\hline calx & ERG screen & $\mathrm{Na}^{+} / \mathrm{Ca}^{2+}$ exchanger & Inactivation of light response \\
\hline cam & Lethality/ERG & $\mathrm{Ca}^{2+}$ regulatory protein; calmodulin & Slow termination \\
\hline$c d s$ & lac $Z$ reporter screen & CDP-DAG synthase & Low light sensitivity \\
\hline $\operatorname{cn} x$ & Retinal degeneration screen & Rhodopsin chaperone; calnexin & No PDA \\
\hline dcamta & ERG screen & $\mathrm{CaM}$ binding transcription factor & Slow termination \\
\hline$d G \alpha_{q}$ & Western blot screen & $\alpha$ subunit of $G$ protein & Low light sensitivity \\
\hline$G \beta_{e}$ & Western blot screen & $\beta$ subunit of $G$ protein & Low light sensitivity \\
\hline$G \gamma_{e}$ & Transgenic flies: dominant negative isoform & $\gamma$ subunit of $\mathrm{G}$ protein & Low light sensitivity \\
\hline GPRK1 & Transgenic flies: dominant negative isoform & Rhodopsin kinase & Larger amplitude \\
\hline inaC & ERG screen & Protein kinase $\mathrm{C}$ & Slow termination \\
\hline inaD & ERG screen & Scaffold protein; 5 PDZ domains & Small response and slow kinetics \\
\hline inaF & ERG screen & Putative regulator of TRP & Transient receptor potential \\
\hline laza & P-element & PA phosphatase & Small response/faster termination \\
\hline $\operatorname{ninaA}$ & ERG screen & Cyclophilin & No PDA \\
\hline $\operatorname{ninaB}$ & ERG screen & $\beta, \beta^{\prime}$-carotene- $15,15^{\prime}$-monoxygenase & No PDA \\
\hline ninaC & ERG screen & Protein kinase/myosin III & Slow termination \\
\hline ninaD & ERG screen & Class B scavenger receptor & No PDA \\
\hline ninaE & ERG screen & Major rhodopsin & No PDA \\
\hline ninaG & ERG screen & Oxidoreductase & No PDA \\
\hline nогрA & Phototaxis screen & Phospholipase C & No response \\
\hline pinta & ERG screen & Retinoid binding & No PDA \\
\hline dpis & Homolous recombination & PI synthase & Inactivation during light response \\
\hline pld & Homolous recombination & Phospholipase D & Low light sensitivity \\
\hline rbo & Paralysis/ERG & Possible lipase in $\mathrm{PIP}_{2}$ pathway & Transient response \\
\hline$r d g A$ & Retinal degeneration screen & DAG kinase & Constitutively active TRP channels \\
\hline$r d g B$ & Retinal degeneration screen & PI transfer protein & Inactivation after light response \\
\hline$r d g C$ & Retinal degeneration screen & Rhodopsin phosphatase & Slow termination \\
\hline santa maria & ERG screen & Class B scavenger receptor & No PDA \\
\hline sun & P-element insertion & Tetraspanin & - \\
\hline $\operatorname{trp}$ & ERG & Cation channel & Transient receptor potential \\
\hline trpl & Western blot screen & Cation channel & No response in combination with trp \\
\hline
\end{tabular}

Listed are the methods used to identify the mutant (or to generate transgenic flies expressing a dominant negative isoform), the proposed molecular functions of the corresponding proteins, and the ERG phenotypes due to loss-of-function mutations.

-Functions in degradation of Rh1

isomerases, cyclophilins, encoded by the ninaA locus [5760]. NINAA is localized predominately in the ER and colocalizes with Rh1 in secretory vesicles. Moreover, NINAA forms a stable and highly specific complex with $\mathrm{Rh} 1$, and gene dosage studies demonstrate a quantitative requirement for NINAA for Rh1 transport [60, 61]. These findings suggest that NINAA functions as a molecular chaperon for $\mathrm{Rh} 1$ rather than as a catalytic enzyme that promotes folding of rhodopsin. Nevertheless, two nina $\mathrm{A}$ alleles display temperature-sensitive peptidyl-prolyl cistrans isomerase activity, suggesting that NINAA may also function catalytically to process $\mathrm{Rh} 1$ through the secretory pathway [62].

The translocation of rhodopsin also requires at least three Rab-GTPases, Rab1, Rab6, and Rab11, which mediate fusion of vesicles through interactions with effector molecules on the target membranes. Rab1 is required for rhodopsin transport between the ER and Golgi complex [63], Rab6 functions in the transport through the ER-Golgi complex [64], and Rab11 mediates post-Golgi translocation of rhodopsin [65]. The function of Rab6 may be rhodopsin-specific, whereas Rab1 and Rab11 operate more generally in the trafficking of membrane proteins in photoreceptor cells [63-65].

Reminiscent of vertebrate rhodopsins, Rh1 undergoes $\mathrm{N}$-linked glycosylation during biosynthesis [66]. The glycosylation takes place at single site (asparagine 20) and is absent from the mature form of Rh1 [67-69]. Mutation of asparagine 20 decreases the level of mature Rh1 and results in retention of this protein in the secretory pathway. In contrast to many proteins that require $\mathrm{N}$-linked glycosylation for interactions with chaperons, N-linked glycosylation of Rh1 does not affect binding to its chaperon, NINAA [69]. 
Fig. 4 Rhodopsin cycle. Rhodopsin is converted into metarhodopsin by light. The receptor is subsequently phosphorylated through action of the GPRK1 and binds arrestin. The conversion of the light-activated metarhodopsin to the rhodopsin requires exposure to a second photon of light. The release of arrestin from the receptor requires $\mathrm{Ca}^{2+} / \mathrm{CaM}$ dependent phosphorylation of Arr2 by CaMKII. The dephosphorylation of the receptor is mediated by $\mathrm{RDGC}$, which is a $\mathrm{Ca}^{2+} / \mathrm{CaM}$ dependent protein phosphatase

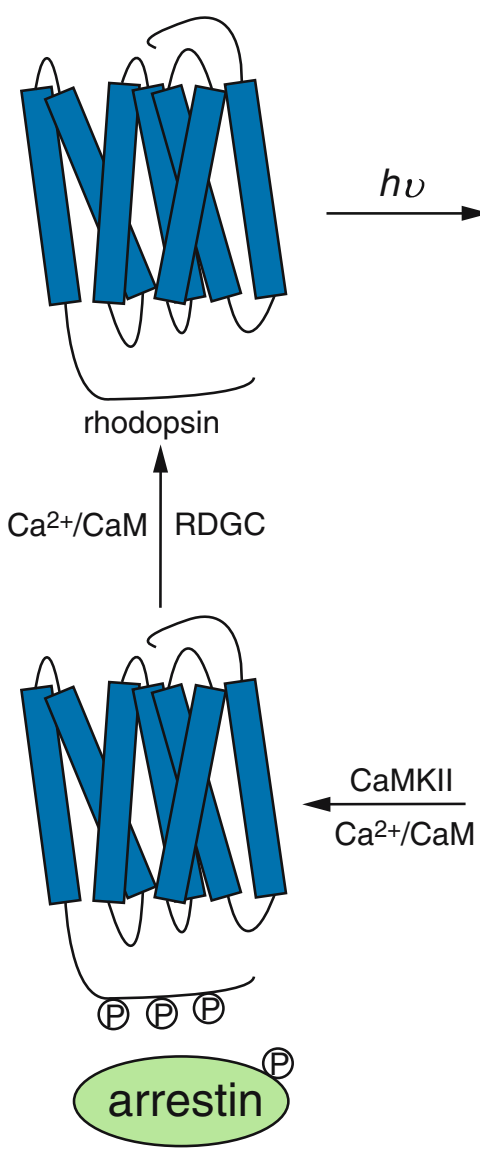

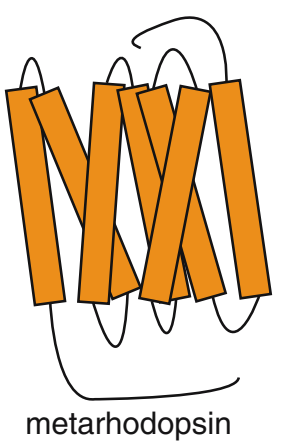
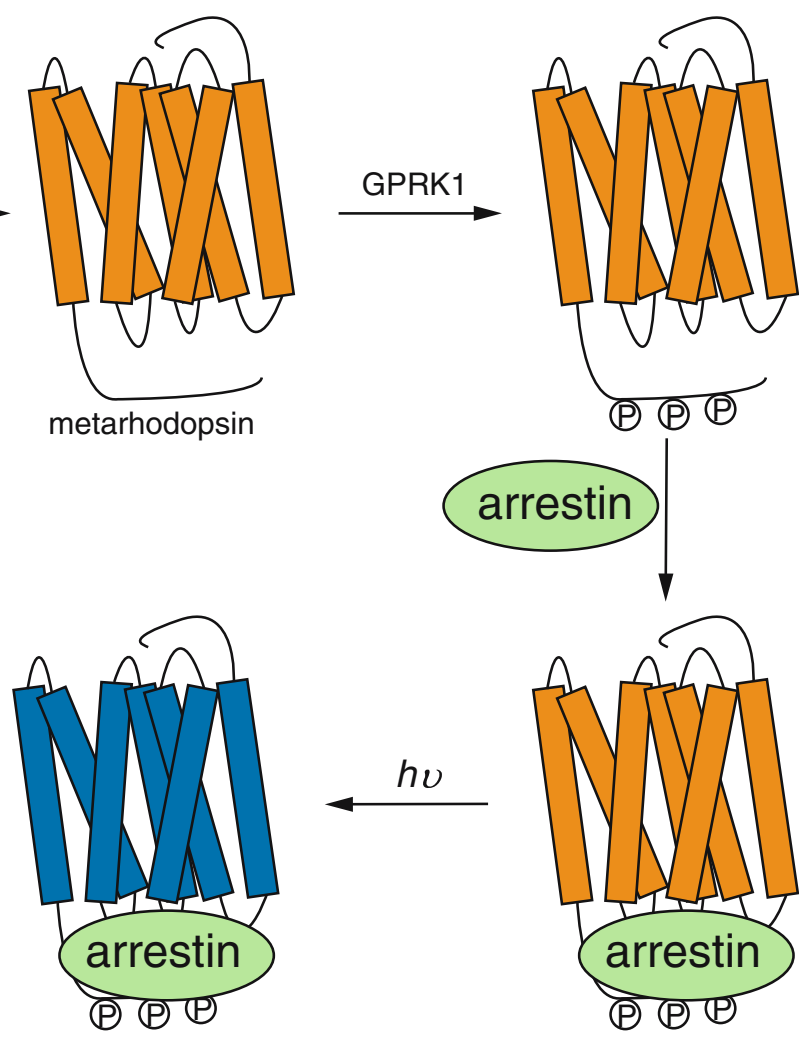

arrestin

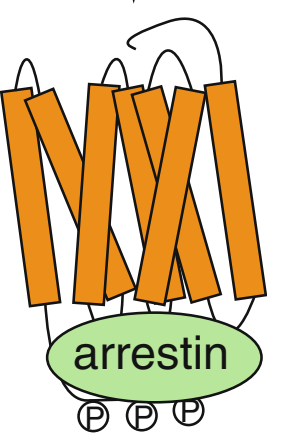

Another ER transmembrane molecular chaperon, calnexin, is required in photoreceptor cells specifically for rhodopsin maturation [70]. Given that other calnexins interact with monoglycosylated glycans present in folding intermediates of glycoproteins, it is plausible that the Drosophila calnexin facilitates the transport of Rh1 through the secretory pathway by binding to the $\mathrm{N}$-linked oligosaccharide attached to asparagine 20 [70].

Genes involved in chromophore biosynthesis: nina, pinta and santa maria

Since rhodopsin is comprised of an opsin and a chromophore, disruption of chromophore biosynthesis prevents

Table 2 Expression patterns and absorption maxima of the Drosophila rhodopsins

\begin{tabular}{llcc}
\hline Rhodopsin & $\begin{array}{l}\text { Expression } \\
\text { pattern }\end{array}$ & $\begin{array}{l}\text { Peak sensitivity } \\
\text { of rhodopsin }(\mathrm{nm})\end{array}$ & $\begin{array}{l}\text { Peak sensitivity of } \\
\text { metarhodopsin }(\mathrm{nm})\end{array}$ \\
\hline Rh1 & R1-R6 & $\sim 486$ & $\sim 566$ \\
Rh2 & ocelli & $\sim 418$ & $\sim 506$ \\
Rh3 & R7 $(\sim 30 \%)$ & $\sim 331$ & $\sim 468$ \\
Rh4 & R7 $(\sim 70 \%)$ & $\sim 355$ & $\sim 470$ \\
Rh5 & R8 $(\sim 30 \%)$ & $\sim 442$ & $\sim 494$ \\
Rh6 & R8 $(\sim 70 \%)$ & $\sim 515$ & $\sim 468$ \\
\hline
\end{tabular}

production of rhodopsin. In Drosophila, defects in the generation of the chromophore cause profound reductions in opsin levels [71], while this is not the case in vertebrate rods and cones [72]. It has been suggested that the chromophore accelerates opsin maturation by facilitating deglycosylation and transport of the opsin [73, 74].

In Drosophila, dietary $\beta$-carotene is the major substrate for production of vitamin A (all-trans retinol), and the vitamin $\mathrm{A}$ is subsequently converted into the chromophore (11-cis 3-hydroxyretinal; Fig. 5). Vitamin A is not required for viability in fruitflies but appears to function exclusively in the synthesis of the visual pigments [73]. As such, mutations affecting vitamin A production can be identified by screening for flies exhibiting a reduced PDA.

Three genes have been characterized that function in the conversion of $\beta$-carotene to vitamin A. Each function outside of the retina and the corresponding mutant phenotypes are rescued by supplementation of the food with vitamin $A$. The nina $B$ gene, which encodes a $\beta, \beta^{\prime}$-carotene-15,15'-monoxygenase (BCO), catalyzes the centric cleavage of carotenoids to all-trans retinal (Fig. 5) [71, 75, 76]. Two other genes, ninaD [71, 77] and santa maria (scavenger receptor acting in neural tissue and majority of rhodopsin is absent) [78] encode proteins related to mammalian class B scavenger receptors. As such, NINAD and SANTA MARIA may mediate the transport of $\beta$-carotene into cells [77-79]. 
Fig. 5 Model for the conversion of dietary $\beta$-carotene to the chromophore. The NINAD scavenger receptor is required for absorption of $\beta$-carotene into the midgut, which is subsequently taken up into extraretinal neurons and glia in the head via the SANTA MARIA scavenger receptor and cleaved by the NINAB BCO. Vitamin A (all-trans retinol) is subsequently transported to the retinal pigment cells where it is converted to the chromophore through a process dependent on the PINTA retinoid-binding protein and the NINAG oxidoreductase. The chromophore is transported to the photoreceptor cells where it binds to the opsin resulting in the generation of rhodopsin

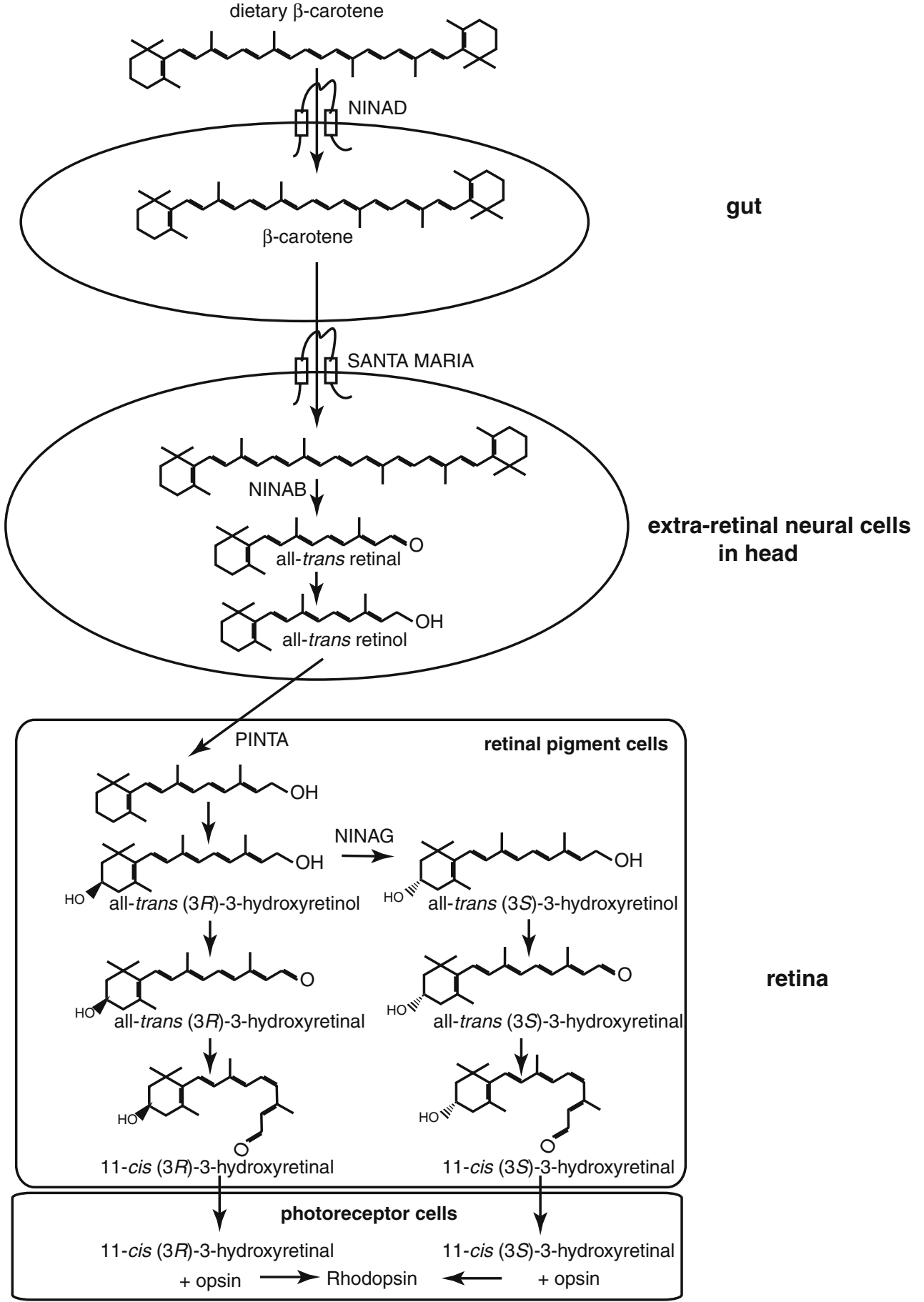

The question arises as to the identity of the scavenger receptor that may function in concert with NINAB. Although NINAD has been suggested to play such a role [80], the different expression patterns of ninaB and ninaD make this hypothesis unlikely [78]. Rather, santa maria and nina $B$ are expressed and function in the same extraretinal glia and neuronal cells in fly heads. Therefore, SANTA MARIA appears to mediate uptake of carotenoids from circulation into both neuronal and glia cells, thereby providing the substrates for processing of carotenoids to retinal by NINAB [78]. NINAD appears to function in the uptake of carotenoids primarily in the midgut [78].

The subsequent conversion of vitamin A to the chromophore takes place in the retina and two genes that function in this transformation have been identified. The pinta (PDA is not apparent) locus [81] encodes a retinoid binding protein, which binds preferentially to all-trans-retinol, and is required in retinal pigment cells for production of the chromophore (Fig. 5). Since in mammals the transformation of dietary vitamin A to 11-cis-retinal occurs in the retinal 
pigment epithelium (RPE) [72], it appears that Drosophila retinal pigment cells are the closest functional equivalent to the RPE. The nina $G$ gene encodes an oxidoreductase, which is proposed to act in the conversion of (3R)-3hydroxyretinol to the $3 \mathrm{~S}$ enantiomer in the compound eye $[82,83]$. However, it is not known whether ninaG functions in the retinal pigment cells or in photoreceptor cells. The conversion of all-trans retinal to 11-cis retinal also takes place in retinal tissues and does so in a light- rather than an enzymedependent manner [84, 85].

The combination of genetic and biochemical analyses permits a pathway to be proposed, which involves multiple cell types, in the conversion of dietary carotenoids to the rhodopsin chromophore (Fig. 5). The pathway begins with the uptake of dietary carotenoids into the midgut, through a process that involves the scavenger receptor NINAD. Instead of being metabolized in the midgut, $\beta$-carotene is delivered to neurons and glia through circulation and taken up into these cells via the SANTA MARIA scavenger receptor. The NINAB BCO subsequently functions in the same neurons and glia as SANTA MARIA in the centric cleavage of $\beta$-carotene to retinal [78]. The all-trans-retinol is then transferred to the retinal pigment cells, where it is converted into the chromophore, through a process involving the PINTA retinoid binding protein and the NINAG oxidoreductase [81, 82]. This proposed pathway is not yet complete as many factors are still unknown. For example, in the mammalian RPE there are several alternative reactions through which all-trans retinol is ultimately converted into the chromophore [86]. However, the proteins involved in the corresponding metabolic events have not been identified in Drosophila, including the relevant retinal dehydrogenases. Candidate dehydrogenases that may function in retinal pigment cells are three eye-enriched short-chain dehydrogenases, which were identified in a microarray analysis for genes preferentially expressed in the retina [31].

\section{The rhodopsin cycle in Drosophila}

Light activation of rhodopsin results in a cis to trans isomerization of the chromophore followed by phosphorylation of the receptor and binding of arrestin (Fig. 4). As is the case with the vertebrate rhodopsins, light-activated Rh1 is phosphorylated in a cluster of serine-threonine residues located in the C-terminal tail [87-89]. In Drosophila, phosphorylation of rhodopsin is catalyzed by a protein kinase (G-protein-coupled kinase 1; GPRK1), which bears greater amino acid sequence identities to mammalian $\beta$ adrenergic receptor kinases than to mammalian rhodopsin kinase [89]. Furthermore, the role of Rh1 phosphorylation by GPRK1 is more akin to the regulation of hormonally stimulated G-protein receptors by $\beta$-adrenergic receptor kinases than phosphorylation of mammalian rhodopsins by rhodopsin kinase. Phosphorylation of Rh1 modulates the amplitude of the visual response because an increase or decrease in GPRK1 activity results in smaller or larger responses, respectively [89].

The termination of rhodopsin activity depends on binding of arrestin, which causes displacement of the $\mathrm{G} \alpha_{\mathrm{q}}$ subunit. It is proposed that the rate of arrestin binding determines the kinetics of rhodopsin inactivation in vivo [90]. In Drosophila, there are two arrestins expressed in photoreceptor cells, arrestin1 and arrestin2 (Arr 1 and Arr 2) [91-93]. Arr2, the major isoform, comprises $\sim 85 \%$ of the total arrestin, whereas the remaining $15 \%$ is Arr1 [94]. Elimination of Arr2 significantly decreases the deactivation rate of the photoresponse, whereas mutation of arr1 has little effect [95]. Nevertheless, Arr1 may also participate in deactivation since termination is more severe when both arrl and arr2 are mutated [95]. Unlike the case with the vertebrate rhodopsins, the binding of Arr2 to Rh1 is not dependent on phosphorylation of Rh1 [96-98]. However, phosphorylation of the C terminus of rhodopsin contributes to Arrl binding and this interaction promotes endocytosis of Rh1, which is proposed to play a role in scavenging spontaneously activated, phosphorylated metarhodopsin [99].

The blue-light-induced PDA requires a molar excess of the Rh1 metarhodopsin over the available arrestin [95]. Normally, the concentration of Rh1 is fivefold higher than arrestin $[94,100]$. Mutations that reduce the Rh1 levels to $<20 \%$ of normal levels result in a molar excess of arrestin, thereby preventing a PDA. A PDA can be restored in flies expressing low levels of Rh1 if the Arr2 levels are also reduced [95]. If the Rh1 concentration is normal, but only the arrestin levels are reduced, a PDA is generated with less light intensity than in wild-type [95]. The minor rhodopsins are also bistable pigments. Misexpression of a minor opsin in the R1-6 photoreceptor cells, in the absence of Rh1, results in the production of a PDA according to the spectral characteristics of the minor rhodopsin $[54,56,101]$. For example, introduction of Rh2 in the R1-R6 cells results in a PDA that is produced at $\sim 420 \mathrm{~nm}$ and terminated at $\sim 520 \mathrm{~nm}$, respectively.

After exposure of the metarhodopsin to a second photon of light, the regeneration of rhodopsin requires the release of Arr2 and dephosphorylation of rhodopsin (Fig. 4). Both of these steps are regulated by $\mathrm{Ca}^{2+} /$ calmodulin $(\mathrm{CaM})$. Arr2 is phosphorylated by $\mathrm{Ca}^{2+} / \mathrm{CaM}$-dependent kinase II and this modification is required for dissociation of the rhodopsin/ Arr2 interaction [87, 102-105].

Once the arrestin is released, rhodopsin is dephosphorylated by a serine/threonine protein phosphatase encoded by the retinal degeneration $C(r d g C)$ locus [30, 96, 104, 106]. Maximal activity of RDGC requires direct interaction with $\mathrm{Ca}^{2+} / \mathrm{CaM}$, which relieves inhibition of the phosphatase activity by an autoinhibitory domain [107]. Mutation of 
$r d g C$ causes hyperphosphorylation of rhodopsin and consequently leads to a notable decrease in the rate of photoresponse deactivation. Normal deactivation kinetics is restored in the $r d g C$ mutant flies by replacing wild-type $\mathrm{Rh} 1$, with the truncated version, $\mathrm{Rh} 1^{\Delta 356}$ which is missing the C-terminal phosphorylation sites [96]. It is proposed that the $\mathrm{C}$ terminus of rhodopsin functions as an autoinhibitory domain and deletion of the Rh1 C terminus may abrogate the requirement for Rh1 phosphorylation for maximal activity [96]. However, an alternative possibility is that hyperphosphorylation of rhodopsin in the $r d g C$ mutant stabilizes the metarhodopsin state.

Based on the work described above, a model for the rhodopsin cycle can be formulated (Fig. 4). Absorption of the first photon converts rhodopsin into metarhodopsin, which is subsequently phosphorylated by GPRK1. Phosphorylated metarhodopsin is thermally stable and binds to arrestin, which promotes deactivation. After absorption of the second photon, the metarhodopsin is converted back to inactive rhodopsin, the arrestin dissociates, and the rhodopsin is dephosphorylated by RDGC.

\section{$G_{q}$ and PLC}

In contrast to the phototransduction cascade in rods and cones, the pathway in Drosophila photoreceptor cells functions through phosphoinositol signaling. A similar cascade may be utilized in ipRGCs, although definitive evidence is lacking [11].

\section{$\mathrm{G}_{\mathrm{q}}$ protein in phototransduction}

The effector for the light-activated rhodopsin is the heterotrimeric G-protein, $\mathrm{G}_{\mathrm{q}}$ and it is encoded by $G \alpha_{q}$ [108-110], $G \beta_{e}[111,112]$, and $G \gamma_{e}[113,114]$, all of which are eyeenriched. After exchange of the guanosine diphosphate (GDP) bound to the $G \alpha_{q}$ for GTP, the $G \alpha_{q}$ and $G \beta \gamma$ subunits dissociate and the activated $\mathrm{G} \alpha_{\mathrm{q}}$-GTP binds to the PLC encoded by norp $A$ (no receptor potential $A$ ) $[5,115]$. The $\mathrm{G} \alpha_{\mathrm{q}}$ is critical for the photoresponse since the $G \alpha_{q}$ mutant $\left(d G_{q}{ }^{l}\right)$ shows a 1,000 -fold loss in light sensitivity [110]. However, $d G_{q}^{l}$ is not a null allele and a small residual light response remains.

The G $\beta \gamma$ subunit also affects activation of the PLC, but this appears to be indirect. A strong allele of $G \beta_{e}$ mutant, $G \beta_{e}^{l}$, displays a $\sim 100$-fold reduction in light sensitivity [111], and a mutation in the farnesylation site of $G \gamma_{e}$ also results in a reduction in light sensitivity [114]. Moreover, light-simulated PLC activity is deficient in the $G \beta_{e}^{l}$ mutant [116]. The contribution of the $G \beta \gamma$ complex to activation seems to be indirect through interaction with $G \alpha_{\mathrm{q}}$, since unlike the $G \alpha_{q}$ subunit, $G \beta \gamma$ does not physically interact with NORPA [115]. The G $\beta \gamma$ subunit is also essential for targeting of $\mathrm{G} \alpha_{\mathrm{q}}$ to the membrane $[117,118]$, and a twofold excess of $G \beta_{e}$ over $G \alpha_{q}$ in wild-type flies prevents spontaneous activity of photoreceptor cells, presumably by suppressing rhodopsin-independent activation of the $\mathrm{G} \alpha_{\mathrm{q}}$ [117]. Since low spontaneous activity is required for high light sensitivity, a decrease in the concentration $G \beta \gamma$ subunit appears to reduce light sensitivity by altering the localization of the $G \alpha_{q}$ subunit and increasing spontaneous activity of the $\mathrm{G} \alpha_{\mathrm{q}}$.

The $G \beta \gamma$ subunit is also required for termination of phototransduction, as the rate of deactivation of photoresponse is decreased in $G \beta_{e}^{1}$ flies [111]. Other G $\beta \gamma$ subunits have been shown to be necessary for phosphorylation of GPCRs by recruiting GPCR kinases to the plasma membrane [119]. Since the Drosophila rhodopsin kinase, GPRK1, interacts with $G \beta_{e}$ [89], it is possible that $G \beta_{e}$ accelerates deactivation of rhodopsin by promoting phosphorylation of rhodopsin.

NORPA exhibits dual phospholipase C and GAP activities during phototransduction

The NORPA PLC, which is activated by the $G \alpha_{\mathrm{q}}-\mathrm{GTP}$, catalyzes the hydrolysis of phosphatidylinositol 4,5-bisphosphate $\left(\mathrm{PIP}_{2}\right)$ to generate inositol 1,4,5-trisphosphate $\left(\mathrm{IP}_{3}\right)$ and diacylglycerol (DAG; Fig. 6a) [5, 91]. The critical role for NORPA for activation is illustrated by the observation that strong alleles of norpA, such as norp $A^{P 24}$, abolish the photoresponse (Fig. 3b) [5]. Weak alleles result in decreases in light sensitivity and activation rates, which are linearly dependent on the levels of PLC activity [120, 121]. Decreases in NORPA levels also result in slower termination of the photoresponse. This latter phenotype reflects a second role for NORPA as a GTPase activating protein (GAP) for the $G \alpha_{\mathrm{q}}$ [122], similar to that originally demonstrated for a mammalian PLC $\beta$ [123]. Thus, NORPA functions both in the activation of phototransduction and as a negative regulator of phototransduction.

At least two different forms of PLCs are encoded by norpA, only one of which (subtype I) is primarily expressed in the retina $[5,124,125]$. As is typical of other phospholipase $C \beta$ proteins, both NORPA isoforms have a membrane binding PH domain, a $\mathrm{Ca}^{2+}$ interacting EF-hand, a divided phospholipase catalytic region consisting of $\mathrm{X}$ and $\mathrm{Y}$ core domains, and a putative $\mathrm{G} \alpha_{\mathrm{q}}$ binding $\mathrm{C} 2$ domain (Fig. $6 \mathrm{~b}$ ). In addition, NORPA has a site that binds the INAD scaffold protein.

Consistent with the domain organization of NORPA, the PLC activity is regulated by $\mathrm{Ca}^{2+}$, both positively and negatively. Elevations in $\mathrm{Ca}^{2+}$ levels in the low range $(10 \mathrm{nM}$ to $1 \mu \mathrm{M})$ augment PLC activity, while higher concentrations of $\mathrm{Ca}^{2+}(>10 \mu \mathrm{M})$ suppress activity $[91,116]$. Using a $\mathrm{PIP}_{2}$ sensor to monitor NORPA activity in vivo, the 


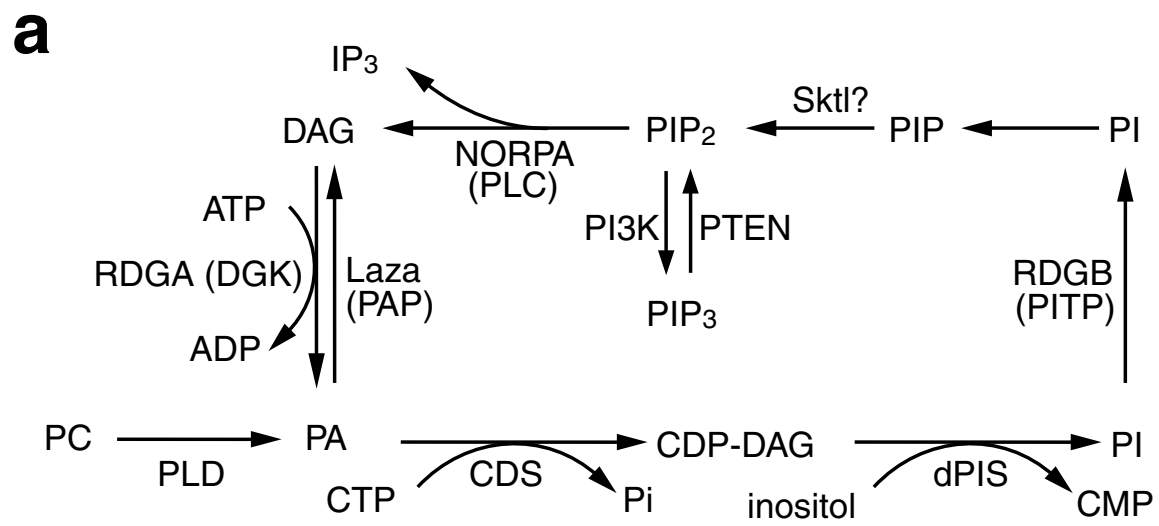

b

\section{NORPA (PLC)}

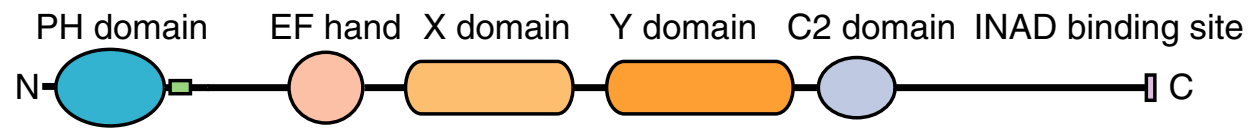

C

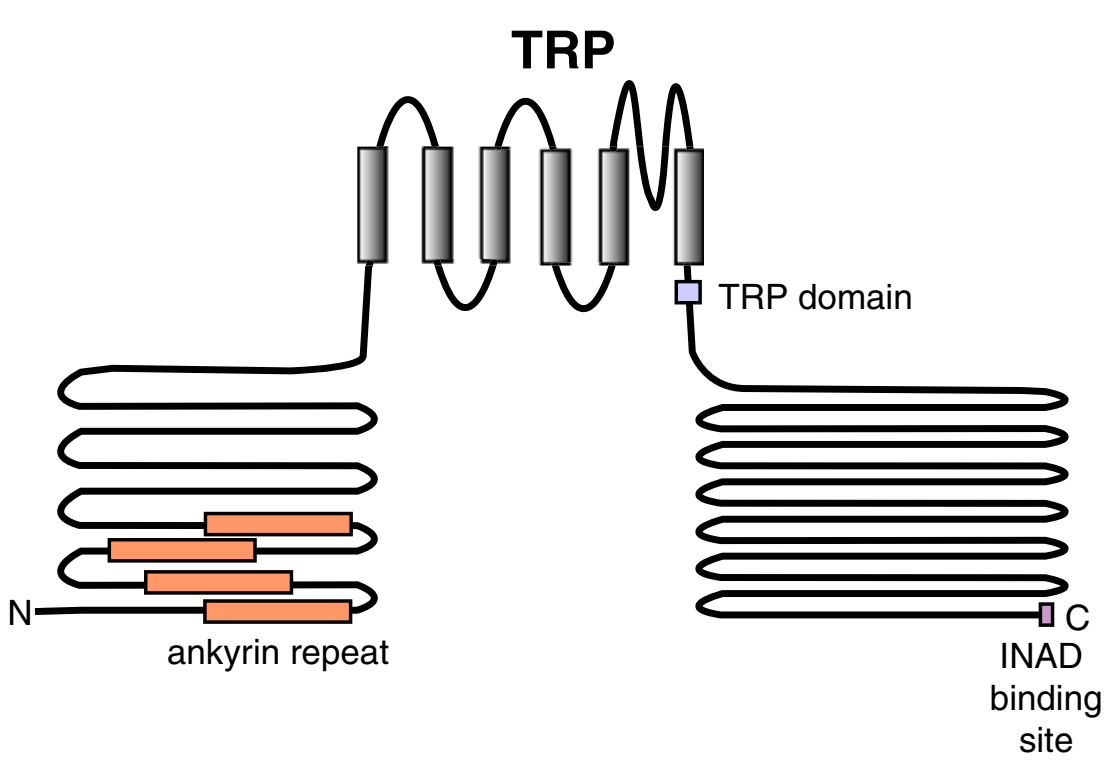

Fig. 6 The $\mathrm{PIP}_{2}$ regeneration cycle and the domain organization of NORPA and TRP. a PIP 2 regeneration cycle. $\mathrm{PIP}_{2}$ is hydrolyzed to $\mathrm{IP}_{3}$ and DAG through action of NORPA. The DAG is converted into PIP through a multistep process that involves the concerted actions of the RDGA DAG kinase (DGK), the CDP-diacylglycerol synthase (CDS), the PI synthase (PIS), and two PI kinases that have not been identified definitively. However, a candidate PIP kinase is encoded by the skittles (sktl) locus [32, 240]. A PI transfer protein (RDGB) is proposed to promote the transfer of PIs from the subrhadomeral cisternae to the rhabdomeres. $\mathrm{PIP}_{2}$ is converted into $\mathrm{PIP}_{3}$ by phosphoinositide 3-kinase (PI3K), and back to $\mathrm{PIP}_{2}$ through the activity of the PTEN phosphatase. A second pathway for production of DAG involves the PLD catalyzed cleavage of phosphatidylcholine $(P C)$ to generate phosphatidic acid $(P A)$, and a PA phosphatase (Laza) promoted conversion of PA to DAG. b Domain organization of NORPA (PLC). Indicated are a possible membrane binding PH domain, an EF-hand, a split phospholipase catalytic region ( $\mathrm{X}$ and $\mathrm{Y}$ core domains), a putative $\mathrm{G} \alpha_{\mathrm{q}}$ binding $\mathrm{C} 2$ domain, which may bind $\mathrm{G} \alpha_{\mathrm{q}}$, and an INAD binding site. The small rectangle adjacent to the $\mathrm{C}$-terminal end of the $\mathrm{PH}$ domain represents a region containing 14 amino acid differences between NORPA subtypes I and II. c Domain organization of TRP. The six vertical rectangles indicate the transmembrane segments. Four ankyrin repeats are situated near the N-terminus. The TRP domain is conserved among all TRPC proteins and some other members of the TRP superfamily [241] 
PLC activity is inhibited by $\mathrm{Ca}^{2+}$ levels $\geq 50 \mu \mathrm{M}[126,127]$. This rapid inhibition of NORPA PLC activity by local $\mathrm{Ca}^{2+}$ transients is proposed to prevent $\mathrm{PIP}_{2}$ depletion during light stimulation [126, 127].

A positive regulator of NORPA activity has been proposed to be Rolling Blackout (RBO), which is distantly related to DAG lipases [128]. Temperature sensitive alleles of $r b o$ result in loss of the photoresponse, if the flies are maintained at the restrictive temperature. An indication that PLC activity is lost in the rbo mutant is that PIP $_{2}$ levels actually rise and the DAG levels decline in response to light, which is the opposite of what should occur if PLCs were active. Whether RBO is a DAG lipase and how it functions in the regulation of NORPA or in the $\mathrm{PIP}_{2}$ regeneration pathway, described in the following section, remains unresolved.

Regeneration of $\mathrm{PIP}_{2}$ and dual pathways for production of DAG

Since hydrolysis of $\mathrm{PIP}_{2}$ is catalyzed by NORPA, the $\mathrm{PIP}_{2}$ must be rapidly replenished to maintain a sustained light response (Fig. 6a). A PI transfer protein and several of the enzymes that function in the $\mathrm{PIP}_{2}$ regeneration cycle have been characterized. In those cases in which the proteins have been spatially localized, they are found in the subrhadomeral cisternae (SRC) situated at the base of the rhabdomeres, or in other vesicles in the extra-rhabdomeral cell bodies [129-131].

Mutations in the first three enzymes that function in the conversion of DAG to $\mathrm{PIP}_{2}$ have been identified. These include the DAG kinase (RDGA), cytidine diphosphate (CDP)-DAG synthase (CDS) and the PI synthase (PIS), which catalyzes the production of phosphatidic acid (PA), CDP-DAG, and PI, respectively (Fig. 6a) [28, 29, 131-133]. In addition, a PI transfer protein (RDGB) may function in the transfer of PIs from the SRC to the rhabdomeres [29, 134, 135]. If the levels of CDS or PIS are reduced but not eliminated, a light response can still be obtained if the flies are dark-adapting [131, 132]. However, the flies are not able to sustain a light response. Conversely, strong $r d g A$ alleles display uncontrolled activity in the photoreceptor cells, even in the dark [136]. The implications of these findings are discussed below in the context of the mechanism of activation of the TRP and TRPL channels.

In addition to hydrolysis of $\mathrm{PIP}_{2}$ by NORPA, there is a second pathway for production of DAG in fly photoreceptor cells. This alternate mechanism involves the concerted action of a phospholipase D (PLD), which cleaves phosphatidylcholine (PC) to generate PA, and a PA phosphatase, referred to as Lazaro (Laza), which subsequently converts the PA to DAG (Fig. 6a) [32, 33, 137]. As with the enzymes involved in regeneration of $\mathrm{PIP}_{2}$, the PLD and Laza are spatially localized to vesicles in the cell bodies [32, 137]. Mutations that disrupt the pld or laza genes diminish the light response indicating that the DAG produced from this second pathway is required for a maximum light response [33, 137]. In addition, the rate of termination of the photoresponse is faster in the laza mutant flies than in wild-type flies [33], suggesting that DAG production under the control of Laza slows down response termination.

\section{The TRPC cation channels}

Activation of NORPA leads to opening of at least two TRPC channels, TRP and TRPL, which are $~ 50 \%$ identical over the N-terminal 700 residues. The TRP channel (Fig. 6c) is the founding member of the TRP superfamily of cation channels $[6,138]$, and mutation of trp results in a transient response to light (Fig. 3c) and a $\sim 10$-fold decrease in $\mathrm{Ca}^{2+}$ influx $[8$, 139]. Disruption of trpl alone results in a decreased response to long light stimulation, but the phenotype is much more subtle than the transient response that is characteristic of trp flies [140]. In addition, the trpl mutant displays a defect in adapting to dim background illumination [140]. Upon elimination of both trp and trpl, the flies are unresponsive to light $[9,141]$.

The subunit composition of the phototranduction channels may consist of TRP homotetramers and TRP/TRPL heteromultimers, although this issue remains controversial. TRP would appear to be present primarily as a homomultimer since it is $\sim 10$-fold more abundant than TRPL [142]. Analyses of TRP in the absence of TRPL (analyzed in the trpl mutant) indicates that the TRP-dependent current is relatively $\mathrm{Ca}^{2+}$ selective $\left(P_{\mathrm{Ca}}: P_{\mathrm{Na}}=100: 1\right)$, with a conductance of $4 \mathrm{pS}$ [141]. The TRPL-dependent current (analyzed in the trp mutant) is nonselective $\left(P_{\mathrm{Ca}}: P_{\mathrm{Na}}=4.1\right)$ and has a higher conductance than TRP (35 pS) [141]. Evidence that TRP and TRPL interact is that they coimmunoprecipitate from fly head extracts and interact in vitro [142]. In addition, TRPL can increase the concentration and activity of TRP when it is not bound to the scaffold protein, INAD [140]. TRPL is constitutively active in vitro; however, TRP/TRPL heteromultimers are regulated channels [142]. However, it has been argued that TRP and TRPL function as two independent homomultimers since the wild-type conductance can be accounted for by the summation of the conductances in the trp and trpl mutants [141]. An additional possibility is that the channels consist of TRP and TRPL homomultimers and TRP/TRPL heteromultimers. A third TRPC channel, TRP $\gamma$, can potentially interact with TRPL [143]. However, it is unclear whether TRP $\gamma$ contributes to the light response, as no loss of function allele of trp $\gamma$ has been described.

An important issue is the mechanism through which TRP and TRPL are activated. Since NORPA is required for activation of the channels, it would appear that gating 
requires production of either $\mathrm{IP}_{3}, \mathrm{DAG}$, or a decrease in inhibitory $\mathrm{PIP}_{2}$. A variety of studies indicate that $\mathrm{IP}_{3}$ is not the critical second messenger. Release of caged $\mathrm{IP}_{3}$ does not mimic the light response [144], and mutation of the only $\mathrm{IP}_{3^{-}}$ receptor encoded in the Drosophila genome has no impact on phototransduction $[145,146]$. Furthermore, $\mathrm{IP}_{3}$ does not activate TRPL in an in vitro expression system [147]. A reduction in PIP $_{2}$ levels also does not appear to be sufficient for activation of the TRP channels in photoreceptor cells since a mutation in the only Drosophila PI synthase, which is required for regeneration of $\mathrm{PIP}_{2}$, leads to a loss of the photoresponse rather than constitutive activation of the channels [131].

It appears that DAG, or a DAG metabolite, is critical for activation of the TRPC channels. In support of this conclusion, introduction of either DAG or PUFAs, such as linolenic acid, results in activation of the channels in photoreceptor cells or in vitro [148]. The channels are constitutively active in the $r d g A$ mutant, which is missing the DAG kinase that metabolizes DAG to PA [136]. Conversely, in a mutant background (laza) that removes the second PLD/PAP pathway for production for production of DAG (Fig. 6a) $[32,33]$, the light response is smaller [33]. The faster termination of the photoresponse in the laza mutant also suggests that Laza-dependent production of DAG contributes to TRPC channel activation. Taken together, these results suggest that DAG is the essential second messenger necessary for activation of TRP and TRPL.

A protein that appears to be required for TRP activity is INAF since the absence of INAF results in an ERG phenotype very similar to that observed in trp mutant flies [149]. Moreover, the photoresponse is nearly eliminated in inaF; trpl double mutant flies. The concentration of TRP is reduced to $\sim 15 \%$ of wild-type levels in the inaF mutant, and this effect appears to be specific as the levels of other proteins analyzed are unaffected. The inaF phenotype is not due simply to the lower concentration of TRP, since expression of TRP at $10 \%$ of the normal levels is sufficient to elicit a wild-type ERG [150]. INAF has no clear homology to other proteins or predicted transmembrane domains, and the mechanism through which it regulates TRP function remains to be elucidated. Nevertheless, INAF is not a chaperone required for rhabdomere localization since TRP displays a typical rhabdomere localization pattern in inaF mutant photoreceptor cells [149].

\section{Extrusion of $\mathrm{Ca}^{2+}$ via the $\mathrm{CalX} \mathrm{Na}^{+} / \mathrm{Ca}^{2+}$ exchanger}

Within $20 \mathrm{~ms}$ of light stimulation, the $\mathrm{Ca}^{2+}$ concentration in the rhabdomeral microvilli can rise from a resting $\mathrm{Ca}^{2+}$ level of $\sim 160 \mathrm{nM}$, to reach peak values higher than $200 \mu \mathrm{M}$, before declining to a steady-state of $\sim 20 \mu \mathrm{M}$ [151-153]. To accomplish the dynamic changes in $\mathrm{Ca}^{2+}$ levels during the photoresponse, a rapid $\mathrm{Ca}^{2+}$ extrusion mechanism is required to counter the TRP-dependent influx of $\mathrm{Ca}^{2+}$. $\mathrm{A} \mathrm{Ca}^{2+}$ efflux mechanism is also necessary to reset the normal resting $\mathrm{Ca}^{2+}$ levels after light stimulation. In Drosophila photoreceptor cells, a $\mathrm{Na}^{+} / \mathrm{Ca}^{2+}$ exchanger, CalX (Fig. 1) [154-156], colocalizes with TRP in the rhabdomeres and is the critical protein that mediates extrusion of $\mathrm{Ca}^{2+}$ [157]. As is typical of other $\mathrm{Na}^{+} / \mathrm{Ca}^{2+}$ exchangers, CalX extrudes one $\mathrm{Ca}^{2+}$ ion in exchange for entry of three $\mathrm{Na}^{+}$ions [154-156].

Analyses of the calx mutant, as well as flies overexpressing calx, show that $\mathrm{Ca}^{2+}$ extrusion through the $\mathrm{Na}^{+} /$ $\mathrm{Ca}^{2+}$ exchanger is required for many events during phototransduction [157] and support other studies indicating that $\mathrm{Ca}^{2+}$ both facilitates and inhibits different aspects of the photoresponse [25]. Loss of calx results in an inability to sustain a photoresponse of normal amplitude (Fig. 3d), hyperadaptation, possibly due to $\mathrm{Ca}^{2+}$-mediated inactivation of the TRP channels, and decreased amplification [157].

\section{Signal amplification requires the $G_{q}$ and NORPA}

A phenomenon in both vertebrate and invertebrate phototransduction is that there is considerable signal amplification. The extent of amplification can be assessed by assaying the size of the quantum bumps (typically $\sim 10 \mathrm{pA}$ ), which is defined by the number of TRPC channels opened by a photon of light. In flies, 25 channels appear to be activated by a single photon [25]. Since each Drosophila microvillus may contain $\sim 25$ channels, it has been proposed that the extent of amplification of the cascade may be dictated by the size of the microvillus $[24,25]$. Indeed, it has been reported that many TRP channels are gated in concert during the light response [158]. An important regulator of amplification is $\mathrm{Ca}^{2+}$, as the size of the quantum bumps is smaller in the calx mutant and larger in flies overexpressing calx [157].

A question concerns the steps in the cascade at which amplification takes place. According to one group, amplification occurs primarily downstream of PLC since mutations that reduce either the $G \alpha_{q}$ or PLC concentration have little effect on the size of the quantum bumps [159]. However, a subsequent study showed that the quantum bump sizes were reduced in both $G \alpha_{q}$ and norpA hypomorphs [26]. The reduced amplitude can be restored in either mutant by inhibiting the metabolism of DAG through mutation of the DAG kinase encoded by $r d g A$ [26]. Since the DAG kinase activity is adenosine triphosphate (ATP)-dependent [26] it is suggested that the earlier results, which conclude that amplification is subsequent to the activity of NORPA [159], is probably due to omission of ATP from the recording electrode [26]. Thus, it appears that amplification occurs at the levels of the $\mathrm{G}_{\mathrm{q}}$ and PLC. The results by Hardie 
et al. [26] also lend further support to the conclusion that DAG is an excitatory second messenger for the TRPC channels.

\section{$\mathrm{Ca}^{2+}$-dependent termination of the photoresponse}

$\mathrm{Ca}^{2+}$ is the critical second messenger that regulates termination of the photoresponse in Drosophila [4, 160, 161]. The central role for $\mathrm{Ca}^{2+}$ in response termination is illustrated by the observations that the termination time is increased either by removing or lowering extracellular $\mathrm{Ca}^{2+}$ from the bath solution during whole-cell recordings from photoreceptor cells $[2,4,25]$ or by overexpressing the $\mathrm{Na}^{+} / \mathrm{Ca}^{2+}$ exchanger, CalX [157]. Conversely, the kinetics of termination is faster if the $\mathrm{Ca}^{2+}$ levels are elevated in the photoreceptor cells either by increasing extracellular $\mathrm{Ca}^{2+}$ during whole-cell recordings, or by genetically removing calx $[2,25,157]$. Several proteins that mediate the $\mathrm{Ca}^{2+}$-regulated termination have been identified, which include protein kinase $\mathrm{C}(\mathrm{PKC}), \mathrm{CaM}$, and the myosin III referred to as NINAC.

Members of the PKC family of serine/threonine protein kinases are activated by $\mathrm{Ca}^{2+}$ and DAG, and an eye-enriched PKC encoded by the inaC (inactivation nor afterpotential $C$ ) locus [162] is localized to the rhabdomeres and is required for deactivation of the visual cascade $[2,163] . \mathrm{Ca}^{2+}$ influx through the TRP channels is much higher in the ina $\mathrm{C}$ mutant than in the wild-type, indicating that INAC is required for inactivation of the TRP channels [161]. TRP is phosphorylated by INAC $[164,165]$ and a mutation that abolishes the primary INAC-dependent phosphorylation site in TRP causes slow termination of the light response [166]. These data suggest that INAC contributes to deactivation, at least in part by directly phosphorylating the TRP channel.

Deactivation in the inaC; trp double mutant is slower than in $\operatorname{trp}$ flies, indicating that TRP is not the only functional target of INAC [163]. The NINAC myosin III, which consists of linked protein kinase and myosin domains [23], is also phosphorylated by PKC in vitro [167]. Mutation of the PKC-dependent phosphorylation sites in NINAC results in an unusual defect in deactivation, suggesting that phosphorylation of NINAC by INAC is required for stable termination of visual cascade [167].

A universal regulator of $\mathrm{Ca}^{2+}$ signaling is the $\mathrm{Ca}^{2+}$-binding regulatory protein $\mathrm{CaM}$, which in the photoreceptor cells is enriched in the rhabdomeres [168]. The subcellular distribution of CaM is dictated by the two NINAC isoforms, p174 and p132, which are localized specifically in the rhabdomeres and cell bodies, respectively [168, 169]. CaM is detected predominately in the cell bodies of photoreceptor cells that express only the p132 isoform and almost exclusively in the rhabdomeres of photoreceptor cells expressing just p174 [169]. A dramatic reduction in rhabdomeral $\mathrm{CaM}$ is also observed if the $\mathrm{CaM}$ binding sites in p174 are mutated. NINAC p174 binds CaM through two sites, $\mathrm{C} 1$ and $\mathrm{C} 2$. The $\mathrm{C} 1$ site is common to both $\mathrm{p} 132$ and p174, whereas C2 is unique to p174. Elimination of either or both sites in p174 results in reduced levels of $\mathrm{CaM}$ in the rhabdomeres and slow termination of the photoresponse $[168,169]$. These data suggest that the defect in response termination is a consequence of low rhabdomeral $\mathrm{CaM}$. However, the results do not exclude that the defect in these flies reflects a role for p174 in response termination, independent of the effects on CaM distribution.

In Drosophila, CaM is encoded by a single gene, cam [170, 171], and null mutations in cam are lethal [172]. Mosaic flies missing cam from the eye display developmental defects. Therefore, the role of cam during the photoresponse was analyzed in homozygous viable hypomorphic alleles, which express a tenfold reduction of CaM [159]. Consistent with the studies on NINAC p174, the cam hypomorphs display a defect in response termination [159].

$\mathrm{CaM}$ is likely to regulate termination of the photoresponse through multiple mechanisms, including effects on the rhodopsin cycle (Fig. 4), and modulation of the cation influx channels. Both TRP [173] and TRPL [7, 174] bind CaM through C-terminal sequences in vitro. In the absence of TRP, expression of a TRPL isoform missing either of two $\mathrm{CaM}$ binding sites leads to remarkably slower termination than that observed in photoreceptors expressing wild-type TRPL only [159]. Thus, it appears that TRPL (and possibly TRP) are physiologically relevant targets for CaM during termination of the photoresponse.

A novel mechanism for $\mathrm{Ca}^{2+} / \mathrm{CaM}$ mediated response termination involves a $\mathrm{CaM}$ binding transcription factor, dCAMTA, and its transcriptional target, $d F b \times 14$, which encodes an F-box protein [175]. Mutations in dcamta result in slow termination of the photoresponse, and this phenotype is reversed by overexpression of $d F b x 14$ [175]. F-box proteins related to dFBX14 function in ubiquitination [176], and some GPCRs are regulated by ubiquitination [177]. Therefore, it is proposed that dFbx14 functions to ubiquitinate rhodopsin, which in turn interferes with activation of the $\mathrm{G} \alpha_{\mathrm{q}}$ [175]. Loss-of-function mutations in $d F b \times 14$ and the mechanisms that regulate its activity remain to be described.

\section{Adaptation}

Short-term adaptation due to inhibition of the TRPC channels

Light adaptation is the phenomenon by which photoreceptor cells alter their sensitivities to light in response to changes in light intensities. Such a phenomenon contributes to the ability 
of photoreceptor cells to maintain a response over a broad range of light intensities. Certain forms of adaptation occur over a long time-scale of a few or many minutes, and one such type of long-term adaptation is described below. Adaptation also takes place over the course of a few seconds, or even on a milliseconds time-scale. It appears that short-term adaptation is highly $\mathrm{Ca}^{2+}$-dependent and does not depend on the eyeenriched PKC [127]. Rather, short-term adaptation occurs subsequent to the activation of the PLC and results from $\mathrm{Ca}^{2+}$-dependent inhibition of the TRP channels [127]. Since this form of adaptation is independent of PKC, it may occur through the CaM that binds to TRP and TRPL; however, this remains to be determined.

Long-term adaptation through Light-dependent translocation of signaling proteins

One mechanism for long-term adaptation in photoreceptors involves dynamic light-dependent movements of signaling proteins into and out of the rhabdomeres. If the flies are maintained in the dark $\sim 80 \%$ of the major arrestin (Arr2) and nearly all of the minor arrestin (Arr1) are localized to the cell bodies; however, after $\sim 5 \mathrm{~min}$ of light exposure, most of the arrestin moves into the rhabdomeres (Fig. 7a) $[97,99]$. This phenomenon of light-dependent translocation of arrestin was first described in mammalian rods [178181]. In animals kept in the dark most of the arrestin is in the inner segment, and after a few minutes of light exposure the arrestin is primarily present in the outer segment (Fig. 7b).

Two questions arise from the light-stimulated shuttling of arrestin. What are the mechanisms underlying these movements, and what are the functions? In the case of Drosophila Arr2, trafficking is dependent on interactions with phosphatidylinositol 3,4,5-trisphosphate $\left(\mathrm{PIP}_{3}\right)$. Mutations in genes that function in PI metabolism or trafficking, such as $r d g B$, $c d s$, and PTEN, impair light-dependent translocation of Arr2 [182]. Arr2 binds to $\mathrm{PIP}_{3}$ in vitro and disruption of the Arr2/ $\mathrm{PI}$ interaction by mutation of the $\mathrm{PIP}_{3}$ binding site $\left(\right.$ arr $\left.2^{3 K / Q}\right)$ results in defective translocation [182]. Flies expressing $\operatorname{arr} 2^{3 K / Q}$ show impairment in long-term adaptation. In wildtype flies, termination of the photoresponse is accelerated by exposure to light. This light-dependent increase in termination kinetics is defective in $a r r 2^{3 K / Q}$ flies [182].

The $\mathrm{G} \alpha_{\mathrm{q}}$-protein also undergoes light-dependent movements, but they are opposite in direction to the arrestin translocation. In the dark, most of the $\mathrm{G} \alpha_{\mathrm{q}}$ is in the rhabdomeres, and then it moves to the cell bodies in the light over the course of a few minutes (Fig. 7a) [118, 183]. In the dark, the $\mathrm{G} \alpha_{\mathrm{q}}$ subsequently returns to the membrane as an inactive GDP form. The same direction and kinetics of movement occur for the G-protein, referred to as transducin, in mammalian rods/cones [184]. Upon exposure to light, the transducin moves from the outer to inner segment, then traffics back to the outer segment in the dark (Fig. 7b).

As expected, the light-dependent shuttling of the Drosophila $\mathrm{G} \alpha_{\mathrm{q}}$ is dependent on rhodopsin; however, it does not require other known signaling proteins, such as NORPA [118, 183], Arr2, PKC, TRP, and TRPL [183]. Thus, there may be other signaling proteins that remain to be identified, which interact with rhodopsin and promote the movement of the $\mathrm{G} \alpha_{\mathrm{q}}$. The movement of the $\mathrm{G} \alpha_{\mathrm{q}}$ may be dependent on interactions with $G \beta \gamma$ subunit, as the kinetics of the lightdependent translocation of $\mathrm{G} \alpha_{\mathrm{q}}$ and the subsequent return to the rhabdomeral membrane are markedly slowed down in the $G \beta_{e}$ mutant [118].

The TRPL channel, but not TRP, also displays lightdependent trafficking between the rhabdomeres and cell body. During light stimulation, TRPL moves from the rhabdomeres to the cell bodies with a half-time of $\sim 30 \mathrm{~min}$ and then translocates back into the rhabdomeres in the dark (Fig. 7a) [185]. If the rhabdomeral TRPL is depleted by maintaining the flies in the light for many hours, there is an ensuing 20-fold increase in rhabdomeral TRPL after $60 \mathrm{~min}$ in the dark [185]. Thus, wild-type flies maintained in the dark have higher levels of rhabdomeral TRPL than flies recently exposed to light. If the flies are kept for long periods in the light, the light-dependent conductance is due almost completely to TRP. Since the $\mathrm{Ca}^{2+}$ selectivity of TRP is much higher than TRPL [141], this change in ratio of TRP and TRPL has physiological consequences. Dark-raised wild-type flies, which have the maximal level of rhabdomeral TRPL, are more sensitive to dim background lights than wild-type flies kept in the light or trpl flies maintained in the dark [185]. These data indicate that TRPL translocation has effects on long-term adaptation.

The mechanism of TRPL translocation appears to be different from the arrestins and $G \alpha_{\mathrm{q}}$ since TRPL is an integral membrane protein. It appears that there are two stages of light-dependent trafficking out of the rhabdomeres. The first stage involves movement of TRPL to the apical membrane adjacent to the rhabdomeres (apical stalk), within $\sim 5 \min$ [186]. The second and slower stage, which takes place over $\sim 6 \mathrm{~h}$, results in localization to the basolateral membrane.

Both stages of the TRPL translocation require rhodopsin activity; however, the mechanisms are otherwise different. The first stage depends on the NORPA PLC but not the TRP channel [186]. Conversely, the second stage requires the TRP channel as well as the PKC encoded by inaC [186]. In flies expressing a constitutively active derivative of TRP [187], TRPL is detected primarily in the basolateral membrane even in the dark [186, 188]. The localization is not due to an obstruction in the movement of TRPL to the rhabdomeres since TRPL is found in the rhabdomeres of very young $\operatorname{Trp}{ }^{P 365}$ flies. 
Fig. 7 Light-dependent movements of signaling proteins. a Translocation of signaling proteins in Drosophila photoreceptor cells. In the dark, arrestin1 and arrestin2 (arrestin) are mostly in the subrhabdomeral cell body, and $\mathrm{G} \alpha_{\mathrm{q}}$ and TRPL are primarily situated in the rhabdomeres. After a few minutes of exposure to light, the arrestins translocate to the rhabdomeres, and the $\mathrm{G} \alpha_{\mathrm{q}}$ and TRPL move to the subrhabdomeral cell bodies. The large white ovals represent the nuclei. b Translocation of signaling proteins in mammalian rods. In the dark, most of the arrestin is in the inner segment and the transducin $\left(G_{t}\right)$ is the outer segment. In the light, the arrestin translocates to the outer segment, and the transducin to the inner segment. The white ovals represent nuclei

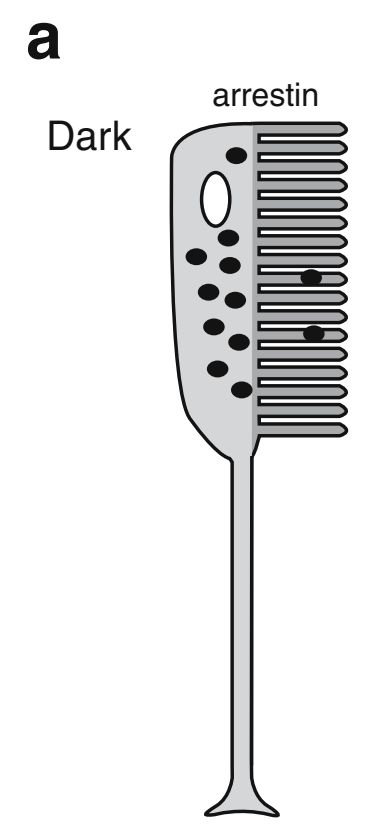

b
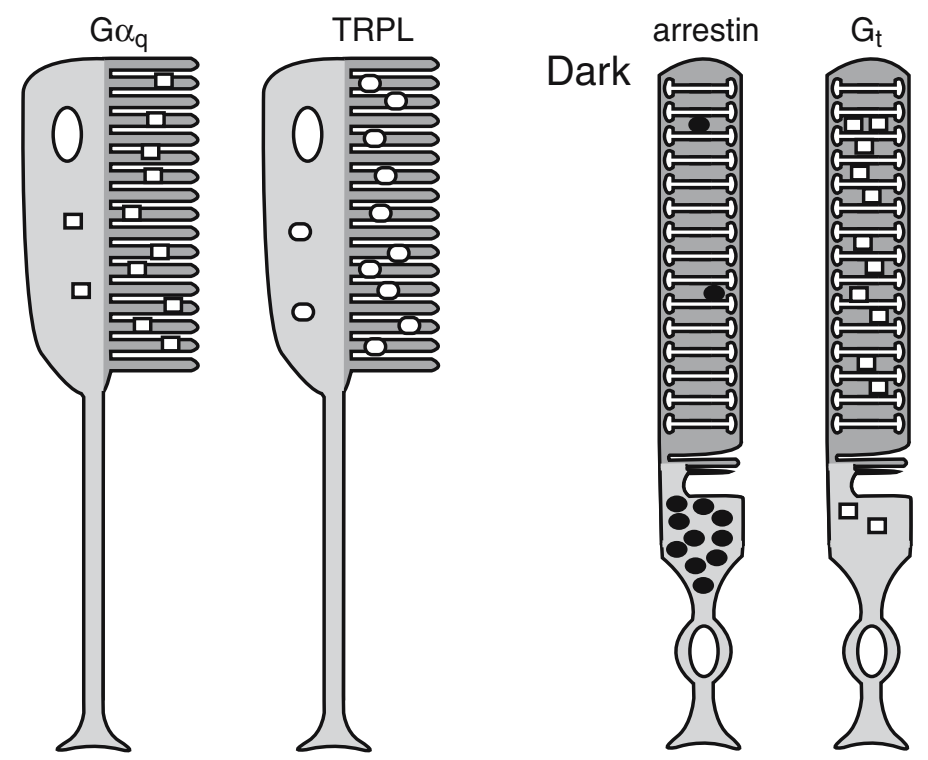

Light
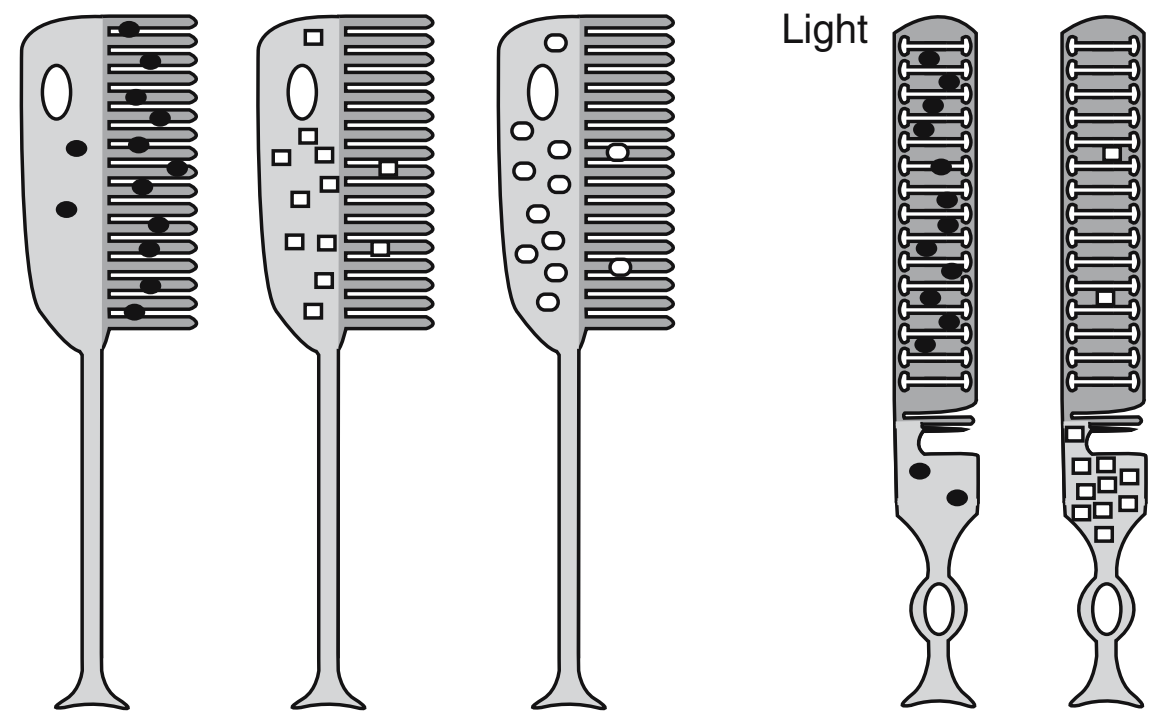

\section{Drosophila}

vertebrate
The dark-mediated re-entry of TRPL into the rhabdomeres may be dependent in part on arrestin since TRPL was mislocalized in an arr2 mutant [186]. Furthermore, the mislocalized TRPL was found in a pattern similar to that observed after the first stage of light-dependent translocation out of the rhabdomeres [186]. Thus, shuttling of TRPL back to the rhabdomeres may also be a two step process. However, in a second study, elimination of both arrl and arr 2 caused a defect in light-induced movement out of the rhabdomeres, rather than dark-mediated shuttling into the rhabdomeres [188]. The basis for this difference is unclear.

Another controversial issue concerns the role of the NINAC myosin III in light-dependent translocations of signaling proteins from the rhabdomeres. According to one report, the light-induced translocation of Arr2 into the rhabdomeres is impaired in the ninaC null mutant nina $C^{P 235}$ and in mutant flies (nina $C^{\Delta 132}$ ) missing the cell bodyspecific p132 isoform [189]. Elimination of p174 alone has no defect, but this rhabdomere-specific isoform also contributes to light-induced translocation since disruption of both p132 and p174 results in a stronger phenotype than that observed in nina $C^{\Delta / 32}[189]$. The nina $C^{\Delta / 32}$ flies display a long-term adaptation defect, consistent with the role of arrestin in long-term adaptation. Moreover, Arr2 and NINAC interact both in vivo and in vitro; however, the association is indirect. As in the case for Arr2, NINAC also binds PIs and 
the Arr2/NINAC interaction is PI-dependent [182, 189]. Amino acid substitutions in Arr2 that disrupt PI binding also abolishes Arr2/NINAC interaction. Therefore, lightdependent translocation of Arr2 into the rhabdomeres requires PI-mediated interactions between Arr2 and NINAC p132 [189]. According to another study, the light-dependent shuttling of neither Arr1 nor Arr2 is dependent on NINAC [99]. The basis for this latter observation is unclear but could be due to a variety of differences in the experimental protocols, which remain to be resolved. Nevertheless, the translocation of the $\mathrm{G} \alpha_{\mathrm{q}}$ from the cell bodies to the rhabdomeres is also dependent on NINAC [183]. In the case of the $\mathrm{G} \alpha_{\mathrm{q}}$, this movement takes place in the dark.

NINAC would be predicted to be required only for movement into the rhabdomeres, since it may be a plus-enddirected motor, based on analyses of a mammalian myosin III [190-192], and the barbed ends of the actin filaments are at the distal end of the rhabdomeres [193]. Consistent with this proposal, NINAC is required for translocation of the $\mathrm{G} \alpha_{\mathrm{q}}$ and Arr2 from the cell bodies to the rhabdomeres, but not for the movement out of the rhabdomeres [183, 189]. However, trafficking of TRPL-eGFP out of the rhabdomeres is reported to be disrupted in the ninaC null mutant [188]. While this could be due to a secondary effect of retinal degeneration in the null mutant flies, no retinal degeneration takes place in nina $C^{\Delta 132}$ flies [194], which exhibit a defect in translocation of Arr2 [189].

\section{The signalplex}

Many of the proteins that function in Drosophila phototransduction are organized into a supramolecular signaling complex (the signalplex; Fig. 8). The central protein in the signalplex is the scaffold protein, INAD, which is comprised of five PDZ protein interaction modules. The "core complex" [195] consists of INAD and three proteins that bind directly to INAD: TRP, INAC (PKC) and NORPA (PLC) $[173,196,197]$. Each of the three target proteins that are included in the core complex is expressed at similar levels [196] and may always be present in the complex as they depend on INAD for normal localization in the rhabdomeres and protein stability $[173,198]$.

It turns out that there is a reciprocal requirement between TRP and INAD for normal spatial distribution. In addition to TRP depending on INAD, the rhabdomere localization of INAD is severely disrupted either in a trp null mutant background or in flies expressing a TRP derivative missing the C-terminal four residues, which are necessary for INAD binding $[195,199]$. Since INAD is required for localization of TRP, PKC and PLC, the entire core complex is destroyed if TRP is eliminated or if the INAD binding site in TRP is deleted [195, 199]. These findings demonstrate that in addition to serving as a $\mathrm{Ca}^{2+}$-permeable channel, TRP also plays an important role as a molecular anchor. This additional role may account for the observations that TRP is present in approximately stoichiometric proportions with INAD [196], which is a level tenfold higher than is necessary for a normal light-response [150]. The mutual requirement for TRP and INAD for localization reflects mutual roles in retention in the rhabdomeres, rather than for targeting [195, 199].

In addition to the core binding proteins, several other proteins bind INAD. These include TRPL, Rh1, NINAC, CaM [200, 201], and the immunophilin, FKBP59 [202]. Noncore binding proteins do not depend on INAD for localization in the rhabdomeres [200, 201]. Nevertheless, the INAD-binding site in NINAC is sufficient to target a heterologous protein ( $\beta$-galactosidase) into the rhabdomeres [201]. This localization is dependent on INAD, since the $\beta$-galactosidase-NINAC fusion protein remains in the cell body in ina $D^{l}$ null mutant flies. It would appear that some of the noncore binding proteins may interact dynamically with INAD since TRPL undergoes lightdependent translocation to the cell bodies, and $\mathrm{Rh} 1$ is more abundant than INAD. Unlike the other INAD-binding proteins, CaM binds to a linker region between two PDZ domains (1 and 2), rather than directly to a PDZ module [200]. More proteins bind to INAD than there are PDZ domains. INAD has the capacity to nucleate a large array of target proteins since it self-assembles into a polymer, and does so through different interaction interfaces in two PDZ domains than those involved in binding other target proteins [200].

A central issue concerns the functions of the INAD/target protein interactions. As described above, the core-binding proteins depend on INAD for localization in the rhabdomeres and for protein stability [173, 198]. It also seems plausible that nucleation of an array of signaling proteins in a complex would promote rapid signaling. However, mutation of the INAD binding site in TRP, which disrupts direct interactions between TRP and INAD, has no major impact on activation or termination of the photoresponse [195].

Interactions of signaling proteins with INAD appear to function in rapid termination of phototransduction. Mutation of the INAD binding site in the eye-enriched PKC (INAC) causes slower response termination [203]. Since the interaction with INAD is required for the normal stability and localization of INAC, it cannot be excluded that the phenotype may simply reflect reduced levels of rhabdomeral INAC. Disruption of the NINAC/INAD interaction, due to mutation of the INAD binding site in NINAC, also causes delayed termination [201]. Given that NINAC does not depend on INAD for protein stability or rhabdomeral localization this phenotype indicates that binding to INAD is essential for rapid response termination.

An additional potential function for the signalplex is that INAD might serve to compartmentalize protein kinases and 


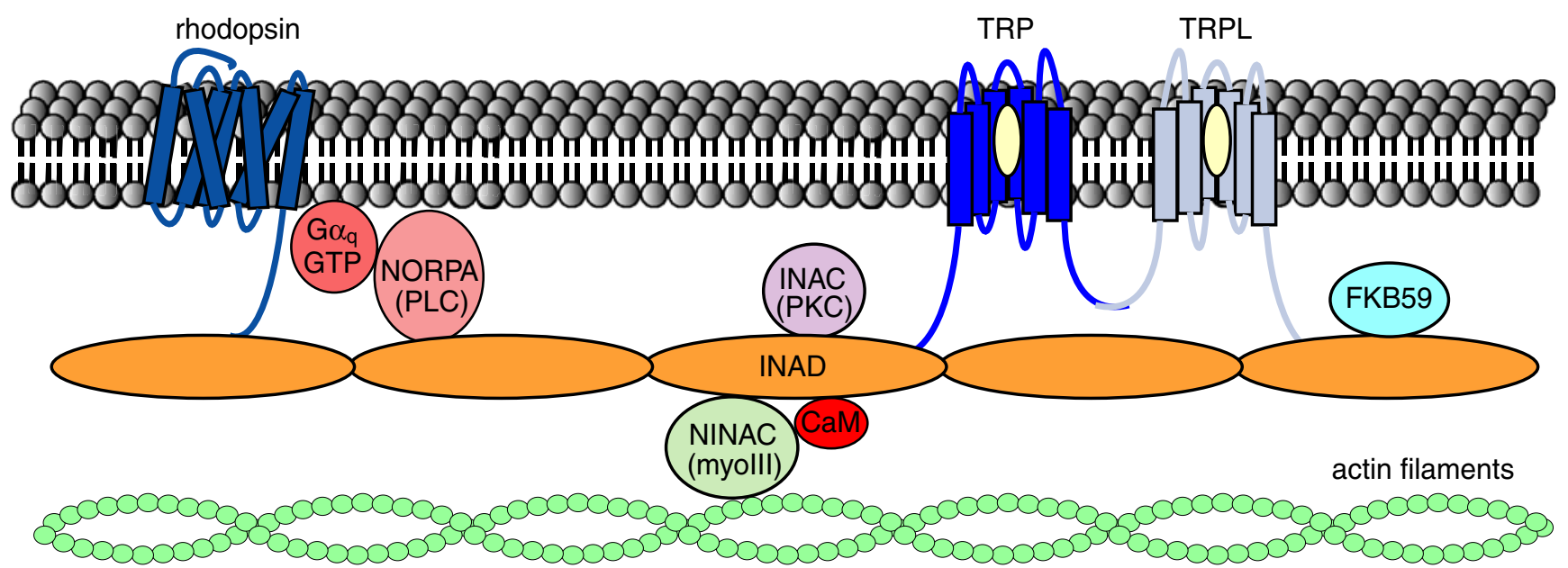

Fig. 8 The signalplex. The "core complex" consists of INAD, TRP, NORPA (PLC) and INAC (PKC). Members of the core complex depend on the signalplex for normal rhabdomere localization. Other members of the signalplex include rhodopsin (Rh1), TRPL, NINAC, CaM and FKB59

substrates into the same complex reminiscent of the complexes containing receptors for activated C-kinase (RACK) [204] and A-kinase anchoring proteins (AKAPs) [205]. At least three members of the signalplex are phosphorylated by PKC: NINAC, INAD and TRP $[164,165]$. In an in vitro assay, PKC phosphorylation of TRP is promoted by INAD and mutation of the major PKC phosphorylation in TRP site results in a slower deactivation kinetics [166]. Furthermore, the deactivation time is slower in flies expressing INAD ${ }^{\mathrm{P} 215}$, which is a derivative of INAD that does not effectively bind TRP [197, 206]. Taken together, these results suggest that INAD facilitates PKC phosphorylation of TRP in vivo, which is necessary for rapid termination. However, the InaD $D^{P 215}$ mutation might affect interactions of INAD with multiple target proteins, and the termination of the photoresponse is normal in flies expressing a derivative of TRP that does not bind INAD [195]. Thus, although it seems likely, it remains unclear whether INAD functions as a RACK-like protein in vivo.

\section{Retinal degeneration}

The Drosophila visual system has proven to be a powerful model for dissecting the molecular mechanisms underlying retinal degeneration. Mutations in almost any gene that functions in phototransduction result in photoreceptor cell death and the majority of the retinal degenerations are lightdependent. The molecular bases underlying the retinal degenerations are diverse (Table 3).

Defective rhodopsin folding, transport or activity causes retinal degeneration

The first mutations linked to retinal degeneration were in ninaE, which encode the major rhodopsin, Rh1 [40, 41,
207, 208]. This observation turned out to have relevance to human retinal dystrophies, as mutations in human rhodopsin were shown subsequently to account for a large proportion of the cases of autosomal dominant retinitis pigmentosa disease (ADRP) [209-213].

Since Rh1 plays a structural role in photoreceptor cells [214], in addition to functioning as a light-receptor, most loss-of-function ninaE alleles result in light-independent retinal degeneration [208, 215]. The degeneration in ninaE is not dependent on the signal transduction cascade as the severity of photoreceptor cell death mutation is not reduced by disruption of the PLC (NORPA), which is required for phototransduction $[215,216]$. The cell death is associated with accumulation of membranes in the subrhabdomeral regions, although there is considerable variation in the severities of the phenotypes.

Many of the mutations in ninaE are dominant [216, 217], as is the case for human ADRP disease resulting from mutations in rhodopsin [209, 210, 218]. The dominance may be attributable to misfolding of the rhodopsin derivatives, which in turn interferes with the posttranslational maturation of wild-type rhodopsin [216, 217, 219]. As a consequence, the levels of mature Rh1 are dramatically reduced.

The dominant ninaE mutations primarily affect the maturation and transport of Rh1 into the rhabdomeres [216, 217]. In Drosophila photoreceptor cells, rhodopsin is synthesized and core-glycosylated in the endoplasmic reticulum (ER), transported through the Golgi, and delivered to the rhabdomeres where it functions in phototransduction. Among the mutations in rhodopsin that affect maturation is one (N20I) that disrupts the N-linked glycosylations site of $\mathrm{Rh} 1$ [69]. The $\mathrm{Rh} 1^{\mathrm{N} 20 \mathrm{I}}$ protein is retained in the secretory pathway, resulting in accumulation of ER cisternae and retinal degeneration.

Mutations in loci encoding molecular chaperones, which are necessary for rhodopsin maturation, also cause retinal 
Table 3 Mutations that lead to retinal degeneration

\begin{tabular}{|c|c|c|}
\hline Mutation & $\begin{array}{l}\text { Light } \\
\text { dependent }\end{array}$ & Possible mechanism \\
\hline arrl & No & Endocytosis of Rh1/Arr2 complex \\
\hline $\operatorname{arr} 2$ & Yes & Increased $\mathrm{Ca}^{2+}$ levels \\
\hline calx & Yes & Increased $\mathrm{Ca}^{2+}$ levels \\
\hline$c d s$ & Yes & Disruption of $\mathrm{PIP}_{2}$ regeneration \\
\hline $\operatorname{cn} x$ & Yes & Increased $\mathrm{Ca}^{2+}$ levels and low rhodopsin \\
\hline crumbs & Yes & NK \\
\hline dpis & Yes & Disruption of $\mathrm{PIP}_{2}$ regeneration \\
\hline inaF & NT & Reduction in TRP-dependent $\mathrm{Ca}^{2+}$ influx \\
\hline laza & Yes & Disruption of PI cycle \\
\hline ninaA & No & Low rhodopsin, accumulation of ER \\
\hline $\operatorname{ninaC}$ & Yes & Increased $\mathrm{Ca}^{2+}$ levels due to low $\mathrm{CaM}$ \\
\hline ninaE & No & Low rhodopsin, accumulation of ER \\
\hline $\begin{array}{l}\text { NinaE } \\
\text { (dominant) }\end{array}$ & No & Interference in rhodopsin maturation \\
\hline norpA & Yes & Endocytosis of Rh1/Arr2 complexes \\
\hline$r d g A$ & No & $\begin{array}{l}\text { Constitutively active channels; } \mathrm{Ca}^{2+} \\
\text { overload }\end{array}$ \\
\hline$r d g B$ & Yes & Disruption of $\mathrm{PIP}_{2}$ regeneration \\
\hline$r d g C$ & Yes & Endocytosis of Rh1/Arr2 complexes \\
\hline sun & Yes & Defective rhodopsin degradation \\
\hline $\operatorname{trp}$ & Yes & Endocytosis of Rh1/Arr2 complexes \\
\hline $\operatorname{Trp}$ (dominant) & No & $\mathrm{Ca}^{2+}$ overload \\
\hline
\end{tabular}

The light-dependence and the possible mechanisms for the retinal generations are indicated.

$N T$, not tested; $N K$, not known

degeneration. One chaperone, NINAA, is a cyclophilin-related protein, which is thought to promote the proper folding of $\mathrm{Rh} 1$ $[57,58,60]$. In the absence of NINAA, Rh1 accumulates in the ER and retinal degeneration ensues. Mutations in the gene encoding another rhodopsin chaperone, calnexin (cnx), result in a phenotype bearing some similarities to ninaA mutant flies [70]. Rh1 accumulates in the ER and there is retinal degeneration; however, in contrast to ninaA, the retinal degeneration in the $c n x$ mutant is enhanced in the presence of light. This latter aspect of the $\operatorname{cnx}$ phenotype most likely reflects an additional role of calnexin as a $\mathrm{Ca}^{2+}$ buffer [70]. Rab6 also appears to be required for rhodopsin maturation, since expression of a dominant negative form of Rab6 causes defective rhodopsin maturation, and trafficking and triggers retinal degeneration [64]. Taken together, these findings demonstrate that disruption in rhodopsin maturation leads to retinal degeneration.

There are at least two possible mechanisms through which defective rhodopsin maturation leads to photoreceptor degeneration. In null or very strong ninaE alleles, the retinal degeneration is a consequence of the structural requirement for rhodopsin during morphogenesis. Rhodopsin may comprise the majority of total membrane protein in the rhabdomeres, and complete absence of Rh1 during development results in architectural defects that initiate during pupal development [215, 217]. Production of even small amounts of Rh1 is sufficient for production of normal rhabdomeres $[217,220]$. However, the level of Rh1 and the degree of retinal degeneration do not always correlate among the dominant NinaE alleles [216, 221]. Rather, retinal degeneration due to dominant NinaE mutations appears to result from inhibition of rhodopsin trafficking, which leads to accumulation of ER cisternae and unfolded rhodopsin in the ER.

Constitutive or uncontrolled activity of rhodopsin can also lead to retinal degeneration, such as in the dominant allele, Nina $E^{P P 100}$ [222]. This retinal degeneration is partially suppressed by mutations in $\operatorname{arr} 2$ or $G \alpha_{q}$, whereas complete suppression is achieved by disrupting both $\operatorname{arr} 2$ and the $G \alpha_{q}$. Mutation of arr2 also leads to light-dependent retinal degeneration presumably due to uncontrolled activity of rhodopsin $[95,103]$. Arrestin is necessary for deactivation of rhodopsin, and the cell death in the arr2 mutant is blocked by the $d G_{q}{ }^{1}$ mutation [95] suggesting that it results from excessive activation of the phototransduction cascade. Loss of arr 2 also leads to decreased endocytosis of $\mathrm{Rh} 1$ as reviewed in the next section.

Endocytosis of stable Rh1/Arr2 complexes leads to retinal degeneration

It appears that during and after light exposure, a small proportion of the rhodopsin pool is removed from the rhabdomeral membrane and degraded, possibly as a quality control mechanism to dispose of photodamaged or constitutively active rhodopsin [98]. Abnormal increases or decreases in the rhodopsin turnover pathway appear to cause retinal degeneration. In wild-type flies, removal of Rh1 is initiated by interactions with Arr1 [99] and Arr2 [223] and subsequent endocytosis of Rh1, which may then be trafficked to lysosomes through direct interactions with a tetraspanin, Sunglasses (Sun), present in the membranes of late endosomes and lysosomes [31]. Mutations in either arr 1, arr 2, or sun result in retinal degeneration because of decreased endocytosis or degradation of rhodopsin. Thus, a defect in degradation of internalized rhodopsin may be toxic. The cell death resulting from loss of arr2 is countered by overexpressing ceramidase [224, 225], which cleaves ceramide to produce sphingosine. The ceramidase may decrease the toxicity resulting from absence of Arr2 by increasing endocytosis [224, 225]. Unlike the light-dependent cell death in sun [31] and arr2 flies [95], the degeneration in arrl is light-independent [99]. However, no degeneration occurs in arr1;arr2 double mutant flies [99]. It is proposed that Arr1 scavenges active rhodopsin by endocytosis and thereby counters toxic Arr2/Rh1 accumulation, as described below [99].

The converse of retinal degeneration resulting from too little endocytosis of rhodopsin is the cell death that occurs 
from excessive endocytosis due to stable interactions between Rh1 and Arr2. Normally, the binding of Arr2 to $\mathrm{Rh} 1$ is transient, as light-induced $\mathrm{Ca}^{2+}$ influx activates $\mathrm{CaM}$ kinase II, which in turn leads to phosphorylation of Arr2 and release from Rh1 [103, 105]. Mutations such as those in trp and norpA that prevent the normal rise in $\mathrm{Ca}^{2+}$ after light stimulation result in stable Rh1/Arr2 complexes and retinal degeneration. Elimination of the rhodopsin phosphatase, RDGC, also promotes stable Rh1/Arr2 complexes [97]. Disruption of Rh1/Arr2 stable complexes either in norpA, trp or $r d g C$, by genetic removal of Arr2, suppresses the retinal degeneration.

For the stable Rh1/Arr2 complexes to cause massive cell death, the Rh1 needs to be internalized, and this is dependent on dynamin and the endocytic adaptor protein, AP-2. Mutation of the dynamin GTPase (shibire), which prevents clathrin-mediated endocytosis, suppresses the retinal degeneration in the $r d g C$ mutant [97]. Loss of the $\alpha$ subunit of AP-2 adaptor complex has been shown to suppress the retinal degeneration in the norpA mutant [223]. Moreover, mutations in arr2 that disrupt the interaction between Arr2 and AP-2 prevent the retinal degeneration in norpA photoreceptor cells [223].

Retinal degeneration due to unregulated $\mathrm{Ca}^{2+}$ levels

Precise control over $\mathrm{Ca}^{2+}$ levels is essential for photoreceptor cell survival [226]. Either high or low levels of $\mathrm{Ca}^{2+}$ are toxic to the cells. A demonstration that abnormally high $\mathrm{Ca}^{2+}$ levels lead to retinal degeneration is that loss of the $\mathrm{Na}^{+} / \mathrm{Ca}^{2+}$ exchanger, CalX causes light-dependent retinal degeneration. The severity of the retinal degeneration is greatly suppressed in the calx,trp double mutant [150]. The $\mathrm{Ca}^{2+}$ levels are also elevated in dark-adapted calx flies, but no degeneration takes place under these conditions. Thus, abnormally high $\mathrm{Ca}^{2+}$ levels do not trigger photoreceptor cell death unless it occurs during phototransduction.

$\operatorname{Trp}^{P 365}$ flies, which express a constitutively active TRP channel, undergo retinal degeneration. Unlike calx, the $\operatorname{Tr} p^{P 365}$ flies exhibit retinal degeneration in the dark, although the cell death is more rapid under a light/dark cycle [187]. The severity of the $\operatorname{Trp}^{P 365}$ phenotype is reduced by overexpressing CalX [157], consistent with the conclusion that the retinal degeneration in $\operatorname{Trp}^{P 365}$ is a consequence of $\mathrm{Ca}^{2+}$ overload. Loss of calnexin (cnx) also results in retinal degeneration and this phenotype is due to increased $\mathrm{Ca}^{2+}$ levels in addition to the defect in $\mathrm{Rh} 1$ maturation as described above, since Cnx serves to buffer $\mathrm{Ca}^{2+}$ in the photoreceptor cell body [70]. The lightdependent retinal degeneration that results from elimination of the NINAC p174 isoform (myosin III) [194] may be due to higher free $\mathrm{Ca}^{2+}$ levels, since elimination of p174 dramatically decreases the concentration of rhabdomeral

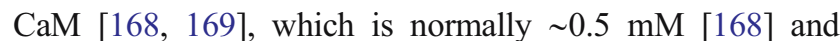
serves as the major $\mathrm{Ca}^{2+}$ buffer in the photoreceptor cells. Excessive $\mathrm{Ca}^{2+}$ influx appears to underlie the very strong retinal degeneration in $r d g A$ flies, which are missing the eyeenriched DAG kinase. The basis for the increased $\mathrm{Ca}^{2+}$ levels in $r d g A$ is described in the following section, which focuses on mutations in the $\mathrm{PIP}_{2}$ regeneration pathway.

Abnormally low light-stimulated rises in $\mathrm{Ca}^{2+}$ levels can also lead to retinal degeneration. The cell death in trp flies is primarily due to the low $\mathrm{Ca}^{2+}$ influx rather than loss of the molecular anchoring function since deletion of the INAD binding site in TRP leads to very mild degeneration, while a mutation $\left(\operatorname{trp}{ }^{14}\right)$ that specifically causes rapid channel inactivation causes retinal degeneration as severe as that caused by null mutations in $\operatorname{trp}{ }^{P 343}[150]$. Both the $t r p^{14}$ and $\operatorname{trp}^{P 343}$ phenotypes are suppressed by loss-of-function mutation in calx and by mutations in arr2 [150]. Thus, the loss of TRP channel function may lead to stable Rh1/Arr2 complexes, and this could result from a defect in $\mathrm{CaM}$ kinase II-dependent phosphorylation of Arr2, which is necessary for dissociation of Arr2 from Rh1 [103, 105].

\section{Disruption of PI cycle leads to retinal degeneration}

Mutations that interrupt the $\mathrm{PIP}_{2}$ regeneration cycle in Drosophila photoreceptor cells (Fig. 6a) cause retinal degeneration. The most profound effects on photoreceptor cell survival result from disruption of the eye-enriched DAG kinase, RDGA, which normally catalyzes the conversion of DAG to PA $[133,227]$. The failure to metabolize DAG in $r d g A$ induces constitutive activity of TRP and TRPL and light-independent retinal degeneration [28, 136]. Overexpression of the eye-enriched PA phosphatase, Lazaro (Laza), which catalyzes dephosphorylation of PA and generation of DAG, enhances both the increased activation of the photoresponse and the retinal degeneration in $r d g A$ mutant, whereas mutation of laza suppresses both aspects of the $r d g A$ phenotype $[32,33]$. Therefore, the increased DAG appears to be the major reason for the retinal degeneration in $r d g A$. Consistent with the concept that DAG contributes to excitation during the photoresponse, the retinal degeneration in the $r d g A$ mutant is suppressed by mutations in trp or norpA [136, 228]. Thus, it is likely that the retinal degeneration in $r d g A$ is caused by excessive $\mathrm{Ca}^{2+}$ influx through constitutively active TRP channels.

Operating in opposition to RDGA is Laza, and mutations that eliminate this PA phosphatase result in light-dependent retinal degeneration $[32,33]$. Laza might function in concert with the PLD to generate DAG through the cleavage of PC to generate PA, which is subsequently converted to DAG (Fig. 6a). Overexpression of the PLD results in lightdependent retinal degeneration [137], which is suppressed by the laza mutation [33]. These data suggest that the retinal 
degeneration resulting from overexpression of PLD is due to excessive production of $\mathrm{DAG}$, which in turn leads to increase channel activity and $\mathrm{Ca}^{2+}$ influx.

Light-dependent retinal degeneration results from disruption of other proteins that function in the $\mathrm{PIP}_{2}$ regeneration cycle, including RDGB (PI transfer protein), CDS (CDP-DAG synthase), and dPIS (PI synthase) [28, 29, 131, 132, 229]. Overexpression of PLD, which might lead to the generation of higher levels of $\mathrm{PIP}_{2}$ through conversion of $\mathrm{PC}$ to $\mathrm{PA}$, suppresses the retinal degeneration in the $r d g B$ mutant [137]. Furthermore, overexpression of dPIS, which generates PI from CDP-DAG, suppresses the $r d g B$ and $c d s$ retinal degeneration phenotypes [131]. Therefore, the retinal degeneration in both the $\operatorname{rdg} B$ and $c d s$ mutants is likely to be due to decreased PIP $_{2}$ levels.

The retinal degeneration associated with $r d g B, c d s$, and dpis might result from decreased light-induced $\mathrm{Ca}^{2+}$ influx since decreased levels of $\mathrm{PIP}_{2}$ would lead to lower channel activity. However, this possibility is counter to the observation that the retinal degeneration in $r d g B$ is suppressed by the trp mutation but not by mutation of the eye-enriched PKC (INAC) [230], which results in slower TRP channel inactivation [166]. Moreover, chemical inhibition of the channels also inhibits the retinal degeneration phenotype of $r d g B$ [231]. Therefore, lower light-induced $\mathrm{Ca}^{2+}$ levels do not appear to be the mode through which $\operatorname{loss}$ of $r d g B$ leads to retinal degeneration.

\section{Distinct effects of phototoxicity on the photoresponse and retinal survival}

In addition to the retinal degeneration resulting from mutations in genes that function in phototransduction, many studies in mammals demonstrate that continuous long-term exposure to light of modest intensity can result in photoreceptor cell death and diminish the photoresponse [232]. The underlying basis of this phototoxicity is poorly understood and it has been presumed that the decrease in the visual response is a secondary consequence of the retinal degeneration. In flies, constant light also causes loss of the photoresponse and retinal degeneration, which is paralleled by a loss of Rh1 [233]. The reduction in Rh1 levels occurs through the formation of stable Rh1/Arr2 complexes.

The visual impairment and retinal degeneration resulting from continuous light occur through distinct mechanisms [233]. Mutations that suppress the decline in Rh1 and loss of the photoresponse, such as arr2, sun, and $R h 1^{\Delta 356}$ (C-terminal truncation of Rh1), do not ameliorate the constant light-induced retinal degeneration. Conversely, mutations known to suppress most retinal degenerations do not protect against light-induced visual impairment. These results indicate that constant light leads to blindness through the formation of stable rhodopsin/Arr2 complexes, which ultimately leads to degradation of rhodopsin.

\section{Concluding remarks}

Despite the diversity in mechanisms underlying photoreceptor cell death in Drosophila, many of the retinal degenerations show features of apoptosis, which is reminiscent of human retinal dystrophies [31, 98, 234, 235]. Although a lot of progress has been made over the past few years, there remain many unanswered questions regarding the mechanisms of retinal degeneration in Drosophila. The trigger that leads to the cell death resulting from endocytosis of Rh1/Arr2 complexes is still unknown. This issue may have bearing on human retinal dystrophies as the phenomenon of retinal degeneration resulting from stable rhodopsin/arrestin complexes has been documented in rodent animal models [236, 237]. Mutations in Drosophila crumbs and its human homolog lead to light-induced retinal degeneration, but the mechanisms underlying these retinal degenerations are poorly understood [238, 239]. The Drosophila retinal pigment cells appear to function similarly to human RPE cells in the generation of the chromophore [81], and many genetic defects in human RPE cells are known to cause photoreceptor cell degeneration. Thus, further characterization of the Drosophila retinal pigment cells is warranted. The work on phototoxicity in Drosophila raises the question as to whether the visual impairment in mammals that results from exposure to continuous light also is due to formation of stable rhodopsin/arrestin complexes and loss of rhodopsin. Finally, the recent indications that the ipRGCs operate through a visual cascade remarkably similar to that in Drosophila [11] have resulted in renewed interest in the mechanism of Drosophila phototransduction.

Acknowledgement The research on phototransduction and retinal degeneration in C. Montell's laboratory is supported by the National Eye Institute.

\section{References}

1. Pak WL, Grossfield J, White NV (1969) Nonphototactic mutants in a study of vision of Drosophila. Nature 222:351-354

2. Ranganathan R, Harris GL, Stevens CF, Zuker CS (1991) A Drosophila mutant defective in extracellular calcium-dependent photoreceptor deactivation and desensitization. Nature 354:230-232

3. Pak WL (1979) Study of photoreceptor function using Drosophila mutants. In: Breakfield XO (ed) Genetic approaches to the nervous system. Elsevier, New York, pp 67-99

4. Hardie RC (1991) Whole-cell recordings of the light induced current in dissociated Drosophila photoreceptors: evidence for feedback by calcium permeating the light-sensitive channels. Proc R Soc Lond B 245:203-210

5. Bloomquist BT, Shortridge RD, Schneuwly S, Perdew M, Montell C, Steller H, Rubin G, Pak WL (1988) Isolation of a 
putative phospholipase $\mathrm{C}$ gene of Drosophila, norp $A$, and its role in phototransduction. Cell 54:723-733

6. Montell C, Rubin GM (1989) Molecular characterization of the Drosophila trp locus: a putative integral membrane protein required for phototransduction. Neuron 2:1313-1323

7. Phillips AM, Bull A, Kelly LE (1992) Identification of a Drosophila gene encoding a calmodulin-binding protein with homology to the trp phototransduction gene. Neuron 8:631-642

8. Hardie RC, Minke B (1992) The trp gene is essential for a lightactivated $\mathrm{Ca}^{2+}$ channel in Drosophila photoreceptors. Neuron 8:643-651

9. Niemeyer BA, Suzuki E, Scott K, Jalink K, Zuker CS (1996) The Drosophila light-activated conductance is composed of the two channels TRP and TRPL. Cell 85:651-659

10. Fu Y, Yau KW (2007) Phototransduction in mouse rods and cones. Pflugers Arch (in press)

11. Berson DM (2007) Phototransduction in ganglion-cell photoreceptors. Pflugers Arch (in press)

12. Provencio I, Jiang G, De Grip WJ, Hayes WP, Rollag MD (1998) Melanopsin: an opsin in melanophores, brain, and eye. Proc Natl Acad Sci USA 95:340-345

13. Provencio I, Rodriguez IR, Jiang G, Hayes WP, Moreira EF, Rollag MD (2000) A novel human opsin in the inner retina. J Neurosci 20:600-605

14. Ruby NF, Brennan TJ, Xie X, Cao V, Franken P, Heller HC, O'Hara BF (2002) Role of melanopsin in circadian responses to light. Science 298:2211-2213

15. Panda S, Sato TK, Castrucci AM, Rollag MD, DeGrip WJ, Hogenesch JB, Provencio I, Kay SA (2002) Melanopsin (Opn4) requirement for normal light-induced circadian phase shifting. Science 298:2213-2216

16. Hattar S, Liao HW, Takao M, Berson DM, Yau KW (2002) Melanopsin-containing retinal ganglion cells: architecture, projections, and intrinsic photosensitivity. Science 295:1065-1070

17. Bellingham J, Whitmore D, Philp AR, Wells DJ, Foster RG (2002) Zebrafish melanopsin: isolation, tissue localisation and phylogenetic position. Brain Res Mol Brain Res 107:128-136

18. Hannibal J, Hindersson P, Knudsen SM, Georg B, Fahrenkrug J (2002) The photopigment melanopsin is exclusively present in pituitary adenylate cyclase-activating polypeptide-containing retinal ganglion cells of the retinohypothalamic tract. J Neurosci 22:RC191

19. Qiu X, Kumbalasiri T, Carlson SM, Wong KY, Krishna V, Provencio I, Berson DM (2005) Induction of photosensitivity by heterologous expression of melanopsin. Nature 433:745-749

20. Panda S, Nayak SK, Campo B, Walker JR, Hogenesch JB, Jegla $\mathrm{T}$ (2005) Illumination of the melanopsin signaling pathway. Science 307:600-604

21. Isoldi MC, Rollag MD, de Lauro Castrucci AM, Provencio I (2005) Rhabdomeric phototransduction initiated by the vertebrate photopigment melanopsin. Proc Natl Acad Sci USA 102:1217-1221

22. Matsumoto H, Isono K, Pye Q, Pak WL (1987) Gene encoding cytoskeletal proteins in Drosophila rhabdomeres. Proc Natl Acad Sci USA 84:985-989

23. Montell C, Rubin GM (1988) The Drosophila ninaC locus encodes two photoreceptor cell specific proteins with domains homologous to protein kinases and the myosin heavy chain head. Cell 52:757-772

24. Postma M, Oberwinkler J, Stavenga DG (1999) Does $\mathrm{Ca}^{2+}$ reach millimolar concentrations after single photon absorption in Drosophila photoreceptor microvilli? Biophys J 77:1811-1823

25. Henderson SR, Reuss H, Hardie RC (2000) Single photon responses in Drosophila photoreceptors and their regulation by $\mathrm{Ca}^{2+}$. J Physiol Lond 524:179-194
26. Hardie RC, Martin F, Cochrane GW, Juusola M, Georgiev P, Raghu P (2002) Molecular basis of amplification in Drosophila phototransduction: roles for $\mathrm{G}$ protein, phospholipase $\mathrm{C}$, and diacylglycerol kinase. Neuron 36:689-701

27. Choe KM, Clandinin TR (2005) Thinking about visual behavior; learning about photoreceptor function. Curr Top Dev Biol 69:187-213

28. Hotta Y, Benzer S (1970) Genetic dissection of the Drosophila nervous system by means of mosaics. Proc Natl Acad Sci USA 67:1156-1163

29. Harris WA, Stark WS (1977) Heriditary retinal degeneration in Drosophila melanogaster: a mutant defect associated with the phototransduction process. J Gen Physiol 69:261-291

30. Steele F, O'Tousa JE (1990) Rhodopsin activation causes retinal degeneration in Drosophila $r d g C$ mutant. Neuron 4:883-890

31. Xu H, Lee SJ, Suzuki E, Dugan KD, Stoddard A, Li HS, Chodosh LA, Montell C (2004) A lysosomal tetraspanin associated with retinal degeneration identified via a genomewide screen. EMBO J 23:811-822

32. Garcia-Murillas I, Pettitt T, Macdonald E, Okkenhaug H, Georgiev P, Trivedi D, Hassan B, Wakelam M, Raghu P (2006) lazaro encodes a lipid phosphate phosphohydrolase that regulates phosphatidylinositol turnover during Drosophila phototransduction. Neuron 49:533-546

33. Kwon Y, Montell C (2006) Dependence on the Lazaro phosphatidic acid phosphatase for the maximum light response. Curr Biol 16:723-729

34. Vogt K, Kirschfeld K (1984) Chemical identity of the chromophores of fly visual pigment. Naturwissenschaften 71:211-213

35. Goldsmith TH, Marks BC, Bernard GD (1986) Separation and identification of geometric isomers of 3-hydroxyretinoids and occurrence in the eyes of insects. Vision Res 26:1763-1769

36. Tanimura T, Isono K, Tsukahara Y (1986) 3-hydroxyretinal as a chromophore of Drosophila melanogaster visual pigment analyzed by high pressure liquid chromatography. Photochem Photobiol 43:225-228

37. Emeis D, Kuhn H, Reichert J, Hofmann KP (1982) Complex formation between metarhodopsin II and GTP-binding protein in bovine photoreceptor membranes leads to a shift of the photoproduct equilibrium. FEBS Lett 143:29-34

38. Kibelbek J, Mitchell DC, Beach JM, Litman BJ (1991) Functional equivalence of metarhodopsin II and the Gtactivating form of photolyzed bovine rhodopsin. Biochemistry 30:6761-6768

39. Kiselev A, Subramaniam S (1994) Activation and regeneration of rhodopsin in the insect visual cycle. Science 266:1369-1373

40. Zuker CS, Cowman AF, Rubin GM (1985) Isolation and structure of a rhodopsin gene from $D$. melanogaster. Cell 40:851-858

41. O’Tousa JE, Baehr W, Martin RL, Hirsh J, Pak WL, Applebury ML (1985) The Drosophila ninaE gene encodes an opsin. Cell 40:839-850

42. Zuker CS, Montell C, Jones K, Laverty T, Rubin GM (1987) A rhodopsin gene expressed in photoreceptor cell R7 of the Drosophila eye: homologies with other signal-transducing molecules. J Neurosci 7:1550-1557

43. Montell C, Jones K, Zuker C, Rubin G (1987) A second opsin gene expressed in the ultraviolet-sensitive R7 photoreceptor cells of Drosophila melanogaster. J Neurosci 7:1558-1566

44. Fryxell KJ, Meyerowitz EM (1987) An opsin gene that is expressed only in the R7 photoreceptor cell of Drosophila. EMBO J 6:443-451

45. Fortini ME, Rubin GM (1990) Analysis of cis-acting requirements of the $R h 3$ and $R h 4$ genes reveals a bipartite organization to rhodopsin promoters in Drosophila melanogaster. Genes Dev $4: 444-463$ 
46. Chou WH, Hall KJ, Wilson DB, Wideman CL, Townson SM, Chadwell LV, Britt SG (1996) Identification of a novel Drosophila opsin reveals specific patterning of the R7 and R8 photoreceptor cells. Neuron 17:1101-1115

47. Papatsenko D, Sheng G, Desplan C (1997) A new rhodopsin in R8 photoreceptors of Drosophila: evidence for coordinate expression with Rh3 in R7 cells. Development 124:1665-1673

48. Salcedo E, Huber A, Henrich S, Chadwell LV, Chou WH, Paulsen R, Britt SG (1999) Blue- and green-absorbing visual pigments of Drosophila: ectopic expression and physiological characterization of the R8 photoreceptor cell-specific Rh5 and Rh6 rhodopsins. J Neurosci 19:10716-10726

49. Chou WH, Huber A, Bentrop J, Schulz S, Schwab K, Chadwell LV, Paulsen R, Britt SG (1999) Patterning of the R7 and R8 photoreceptor cells of Drosophila: evidence for induced and default cell-fate specification. Development 126:607-616

50. Franceschini N, Kirschfeld K, Minke B (1981) Fluorescence of photoreceptor cells observed in vivo. Science 213:1264-1267

51. Kirschfeld K, Feiler R, Franceschini N (1978) A photostable pigment within the rhabdomeres of fly photoreceptors no. 7. J Comp Physiol 125:275-284

52. Hardie RC (1979) Electrophysiological analysis of fly retina. I: Comparative properties of R 1-6 and R 7 and 8. J Comp Physiol 129:19-33

53. Cowman AF, Zuker CS, Rubin GM (1986) An opsin gene expressed in only one photoreceptor cell type of the Drosophila eye. Cell 44:705-710

54. Feiler R, Harris WA, Kirschfeld K, Wehrhahn C, Zuker CS (1988) Targeted misexpression of a Drosophila opsin gene leads to altered visual function. Nature 333:737-741

55. Pollock JA, Benzer S (1988) Transcript localization of four opsin genes in the three visual organs of Drosophila; RH2 is ocellus specific. Nature 333:779-782

56. Zuker CS, Mismer D, Hardy R, Rubin GM (1988) Ectopic expression of a minor Drosophila opsin in the major photoreceptor cell class: distinguishing the role of primary receptor and cellular context. Cell 53:475-482

57. Schneuwly S, Shortridge RD, Larrivee DC, Ono T, Ozaki M, Pak WL (1989) Drosophila ninaA gene encodes an eye-specific cyclophilin (cyclosporine A binding protein). Proc Natl Acad Sci USA 86:5390-5394

58. Shieh B-H, Stamnes M, Seavello S, Harris G, Zuker C (1989) The ninaA gene required for visual transduction in Drosophila encodes ahomologue of cyclosporin A-binding protein. Nature 338:67-70

59. Stamnes MA, Shieh BH, Chuman L, Harris GL, Zuker CS (1991) The cyclophilin homolog ninaA is a tissue-specific integral membrane protein required for the proper synthesis of a subset of Drosophila rhodopsins. Cell 65:219-227

60. Colley NJ, Baker EK, Stamnes MA, Zuker CS (1991) The cyclophilin homolog NinaA is required in the secretory pathway. Cell 67:255-263

61. Baker EK, Colley NJ, Zuker CS (1994) The cyclophilin homolog NinaA functions as a chaperone, forming a stable complex in vivo with its protein target rhodopsin. EMBO J 13:4886-4895

62. Ondek B, Hardy RW, Baker EK, Stamnes MA, Shieh BH, Zuker CS (1992) Genetic dissection of cyclophilin function. Saturation mutagenesis of the Drosophila cyclophilin homolog ninaA. J Biol Chem 267:16460-16466

63. Satoh A, Tokunaga F, Kawamura S, Ozaki K (1997) In situ inhibition of vesicle transport and protein processing in the dominant negative Rab1 mutant of Drosophila. J Cell Sci 110:2943-2953

64. Shetty KM, Kurada P, O’Tousa JE (1998) Rab6 regulation of rhodopsin transport in Drosophila. J Biol Chem 273:2042520430
65. Satoh AK, O’Tousa JE, Ozaki K, Ready DF (2005) Rab11 mediates post-Golgi trafficking of rhodopsin to the photosensitive apical membrane of Drosophila photoreceptors. Development 132:1487-1497

66. O'Tousa JE (1992) Requirement of N-linked glycosylation site in Drosophila rhodopsin. Vis Neurosci 8:385-390

67. Huber A, Smith DP, Zuker CS, Paulsen R (1990) Opsin of Calliphora peripheral photoreceptors R1-6. Homology with Drosophila Rh1 and posttranslational processing. J Biol Chem 265:17906-179010

68. Katanosaka K, Tokunaga F, Kawamura S, Ozaki K (1998) Nlinked glycosylation of Drosophila rhodopsin occurs exclusively in the amino-terminal domain and functions in rhodopsin maturation. FEBS Lett 424:149-154

69. Webel R, Menon I, O'Tousa JE, Colley NJ (2000) Role of asparagine-linked oligosaccharides in rhodopsin maturation and association with its molecular chaperone, NinaA. J Biol Chem 275:24752-24759

70. Rosenbaum EE, Hardie RC, Colley NJ (2006) Calnexin is essential for rhodopsin maturation, $\mathrm{Ca}^{2+}$ regulation, and photoreceptor cell survival. Neuron 49:229-241

71. Stephenson RS, O’Tousa J, Scavarda NJ, Randall LL, Pak WL (1983) Drosophila mutants with reduced rhodopsin content. Symp Soc Exp Biol 36:477-501

72. Travis GH, Golczak M, Moise AR, Palczewski K (2007) Diseases caused by defects in the visual cycle: retinoids as potential therapeutic agents. Annu Rev Pharmacol Toxicol 47:469-512

73. Harris WA, Ready DF, Lipson ED, Hudspeth AJ, Stark WS (1977) Vitamin A deprivation and Drosophila photopigments. Nature 266:648-650

74. Ozaki K, Nagatani H, Ozaki M, Tokunaga F (1993) Maturation of major Drosophila rhodopsin, ninaE, requires chromophore 3hydroxyretinal. Neuron 10:1113-1119

75. von Lintig J, Vogt K (2000) Filling the gap in vitamin A research. Molecular identification of an enzyme cleaving $\beta$ carotene to retinal. J Biol Chem 275:11915-11920

76. von Lintig J, Dreher A, Kiefer C, Wernet MF, Vogt K (2001) Analysis of the blind Drosophila mutant ninaB identifies the gene encoding the key enzyme for vitamin A formation in vivo. Proc Natl Acad Sci USA 98:1130-1135

77. Kiefer C, Sumser E, Wernet MF, Von Lintig J (2002) A class B scavenger receptor mediates the cellular uptake of carotenoids in Drosophila. Proc Natl Acad Sci USA 99:10581-10586

78. Wang T, Jiao Y, Montell C (2007) Dissection of the pathway required for generation of vitamin A and for Drosophila phototransduction. J Cell Biol 177:305-316

79. Voolstra O, Kiefer C, Hoehne M, Welsch R, Vogt K, von Lintig J (2006) The Drosophila class B scavenger receptor NinaD-I is a cell surface receptor mediating carotenoid transport for visual chromophore synthesis. Biochemistry 45:13429-13437

80. Gu G, Yang J, Mitchell KA, O'Tousa JE (2004) Drosophila $\mathrm{NinaB}$ and NinaD act outside of retina to produce rhodopsin chromophore. J Biol Chem 279:18608-186013

81. Wang T, Montell C (2005) Rhodopsin formation in Drosophila is dependent on the PINTA retinoid-binding protein. J Neurosci 25:5187-5194

82. Sarfare S, Ahmad ST, Joyce MV, Boggess B, O'Tousa JE (2005) The Drosophila ninaG oxidoreductase acts in visual pigment chromophore production. J Biol Chem 280:11895-11901

83. Ahmad ST, Joyce MV, Boggess B, O'Tousa JE (2006) The role of Drosophila ninaG oxidoreductase in visual pigment chromophore biogenesis. J Biol Chem 281:9205-9209

84. Schwemer J, Henning U (1984) Morphological correlates of visual pigment turnover in photoreceptors of the fly, Calliphora erythrocephala. Cell Tissue Res 236:293-303 
85. Isono K, Tanimura T, Oda Y, Tsukahara Y (1988) Dependency on light and vitamin A derivatives of the biogenesis of 3hydroxyretinal and visual pigment in the compound eyes of Drosophila melanogaster. J Gen Physiol 92:587-600

86. Rohrer B, Goletz P, Znoiko S, Ablonczy Z, Ma JX, Redmond TM, Crouch RK (2003) Correlation of regenerable opsin with rod ERG signal in Rpe $65^{-/-}$mice during development and aging. Invest Ophthalmol Vis Sci 44:310-315

87. Matsumoto H, Pak WL (1984) Light-induced phosphorylation of retina-specific polypeptides of Drosophila in vivo. Science 223:184-186

88. Cassill JA, Whitney M, Joazeiro CA, Becker A, Zuker CS (1991) Isolation of Drosophila genes encoding G protein-coupled receptor kinases. Proc Natl Acad Sci USA 88:11067-11070

89. Lee SJ, Xu H, Montell C (2004) Rhodopsin kinase activity modulates the amplitude of the visual response in Drosophila. Proc Natl Acad Sci USA 101:11874-11879

90. Ranganathan R, Stevens CF (1995) Arrestin binding determines the rate of inactivation of the $G$ protein-coupled receptor rhodopsin in vivo. Cell 81:841-848

91. Toyoshima $\mathrm{S}$, Matsumoto $\mathrm{N}$, Wang $\mathrm{P}$, Inoue $\mathrm{H}$, Yoshioka $\mathrm{T}$, Hotta Y, Osawa T (1990) Purification and partial amino acid sequences of phosphoinositide-specific phospholipase $\mathrm{C}$ of Drosophila eye. J Biol Chem 265:14842-14848

92. Smith DP, Shieh B-H, Zuker CS (1990) Isolation and structure of an arrestin gene from Drosophila. Proc Natl Acad Sci USA 87:1003-1007

93. Hyde DR, Mecklenburg KL, Pollock JA, Vihtelic TS, Benzer S (1990) Twenty Drosophila visual system cDNA clones: one is a homolog of human arrestin. Proc Natl Acad Sci USA 87:1008-1012

94. Matsumoto H, Yamada T (1991) Phosrestins I and II: arrestin homologs which undergo differential light-induced phosphorylation in the Drosophila photoreceptor in vivo. Biochem Biophys Res Commun 177:1306-1312

95. Dolph PJ, Ranganathan R, Colley NJ, Hardy RW, Socolich M, Zuker CS (1993) Arrestin function in inactivation of G proteincoupled receptor rhodopsin in vivo. Science 260:1910-1916

96. Vinós J, Jalink K, Hardy RW, Britt SG, Zuker CS (1997) A G protein-coupled receptor phosphatase required for rhodopsin function. Science 277:687-690

97. Kiselev A, Socolich M, Vinos J, Hardy RW, Zuker CS, Ranganathan R (2000) A molecular pathway for light-dependent photoreceptor apoptosis in Drosophila. Neuron 28:139-152

98. Alloway PG, Howard L, Dolph PJ (2000) The formation of stable rhodopsin-arrestin complexes induces apoptosis and photoreceptor cell degeneration. Neuron 28:129-138

99. Satoh AK, Ready DF (2005) Arrestin1 mediates light-dependent rhodopsin endocytosis and cell survival. Curr Biol 15:1722-1733

100. LeVine III H, Smith DP, Whitney M, Malicki DM, Dolph PJ, Smith GFH, Burkhart W, Zuker CS (1991) Isolation of a novel visual-system-specific arrestin: an in vivo substrate for lightdependent phosphorylation. Mech Dev 33:19-26

101. Feiler R, Bjornson R, Kirschfeld K, Mismer D, Rubin GM, Smith DP, Socolich M, Zuker CS (1992) Ectopic expression of ultravioletrhodopsins in the blue photoreceptor cells of Drosophila: visual physiology and photochemistry of transgenic animals. J Neurosci 12:3862-3868

102. Kahn ES, Matsumoto H (1997) Calcium/calmodulin-dependent kinase II phosphorylates Drosophila visual arrestin. J Neurochem 68:169-175

103. Alloway PG, Dolph PJ (1999) A role for the light-dependent phosphorylation of visual arrestin. Proc Natl Acad Sci USA 96:6072-6077

104. Byk T, Bar-Yaacov M, Doza YN, Minke B, Selinger Z (1993) Regulatory arrestin cycle secures the fidelity and maintenance of the fly photoreceptor cell. Proc Natl Acad Sci USA 90:1907-1911
105. Matsumoto H, Kurien BT, Takagi Y, Kahn ES, Kinumi T, Komori N, Yamada T, Hayashi F, Isono K, Pak WL, Jackson KW, Tobin SL (1994) Phosrestin I undergoes the earliest light-induced phosphorylation by a calcium/calmodulin-dependent protein kinase in Drosophila photoreceptors. Neuron 12:997-1010

106. Steele FR, Washburn T, Rieger R, O’Tousa JE (1992) Drosophila retinal degeneration $C(r d g C)$ encodes a novel serine/threonine protein phosphatase. Cell 69:669-676

107. Lee SJ, Montell C (2001) Regulation of the rhodopsin protein phosphatase, RDGC, through interaction with calmodulin. Neuron 32:1097-1106

108. Lee Y-J, Shah S, Suzuki E, Zars T, O’Day PM, Hyde DR (1994) The Drosophila $d g q$ gene encodes a $\mathrm{G}_{\alpha}$ protein that mediates phototransduction. Neuron 13:1143-1157

109. Lee Y-J, Dobbs MB, Verardi ML, Hyde DR (1990) $d g q$, a Drosophila gene encoding a visual system-specific $\mathrm{G}_{\alpha}$ molecule. Neuron 5:889-898

110. Scott K, Becker A, Sun Y, Hardy R, Zuker C (1995) $\mathrm{G}_{\mathrm{q} \alpha}$ protein function in vivo: genetic dissection of its role in photoreceptor cell physiology. Neuron 15:919-927

111. Dolph PJ, Man-Son-Hing H, Yarfitz S, Colley NJ, Deer JR, Spencer M, Hurley JB, Zuker CS (1994) An eye-specific $\mathrm{G}_{\beta}$ subunit essential for termination of the phototransduction cascade. Nature 370:59-61

112. Yarfitz S, Niemi GA, McConnell JL, Fitch CL, Hurley JB (1991) $A \mathrm{G}_{\beta}$ protein in the Drosophila compound eye is different from that in the brain. Neuron 7:429-438

113. Schulz S, Huber A, Schwab K, Paulsen R (1999) A novel $\mathrm{G}_{\gamma}$ isolated from Drosophila constitutes a visual G protein $\gamma$ subunit of the fly compound eye. J Biol Chem 274:37605-37610

114. Schillo S, Belusic G, Hartmann K, Franz C, Kühl B, BrennerWeiss G, Paulsen R, Huber A (2004) Targeted mutagenesis of the farnesylation site of Drosophila Gye disrupts membrane association of the $G$ protein $\beta \gamma$ complex and affects the light sensitivity of the visual system. J Biol Chem 279:36309-36316

115. Bähner M, Sander P, Paulsen R, Huber A (2000) The visual G protein of fly photoreceptors interacts with the PDZ domain assembled INAD signaling complex via direct binding of activated $\mathrm{G}_{\alpha \mathrm{q}}$ to phospholipase $\mathrm{C}_{\beta}$. J Biol Chem 275:2901-2904

116. Running Deer JL, Hurley JB, Yarfitz SL (1995) G protein control of Drosophila photoreceptor phospholipase C. J Biol Chem 270:12623-12628

117. Elia N, Frechter S, Gedi Y, Minke B, Selinger Z (2005) Excess of $\mathrm{G}_{\beta \mathrm{e}}$ over $\mathrm{Gq}_{\alpha \mathrm{e}}$ in vivo prevents dark, spontaneous activity of Drosophila photoreceptors. J Cell Biol 171:517-526

118. Kosloff M, Elia N, Joel-Almagor T, Timberg R, Zars TD, Hyde DR, Minke B, Selinger Z (2003) Regulation of light-dependent $\mathrm{G}_{\mathrm{q} \alpha}$ translocation and morphological changes in fly photoreceptors. EMBO J 22:459-468

119. Pitcher JA, Inglese J, Higgins JB, Arriza JL, Casey PJ, Kim C, Benovic JL, Kwatra MM, Caron MG, Lefkowitz RJ (1992) Role of $\beta \gamma$ subunits of $G$ proteins in targeting the $\beta$-adrenergic receptor kinase to membrane-bound receptors. Science 257:1264-1267

120. Pearn MT, Randall LL, Shortridge RD, Burg MG, Pak WL (1996) Molecular, biochemical, and electrophysiological characterization of Drosophila norpA mutants. J Biol Chem 271:4937-4945

121. Pak WL, Ostroy SE, Deland MC, Wu CF (1976) Photoreceptor mutant of Drosophila: is protein involved in intermediate steps of phototransduction? Science 194:956-959

122. Cook B, Bar-Yaacov M, Cohen-BenAmi H, Goldstein RE, Paroush Z, Selinger Z, Minke B (2000) Phospholipase C and termination of G-protein mediated signalling in vivo. Nat Cell Biol 2:296-301

123. Berstein G, Blank JL, Jhon DY, Exton JH, Rhee SG, Ross EM (1992) Phospholipase C- $\beta 1$ is a GTPase-activating protein for $\mathrm{Gq} / 11$, its physiologic regulator. Cell 70:411-418 
124. Schneuwly S, Burg MG, Landing C, Perdew MH, Pak WL (1991) Properties of photoreceptor-specific phospholipase C encoded by the norpA gene of Drosophila melanogaster. J Biol Chem 266:24314-24319

125. Kim S, McKay RR, Miller K, Shortridge RD (1995) Multiple subtypes of phospholipase $\mathrm{C}$ are encoded by the norp $A$ gene of Drosophila melanogaster. J Biol Chem 270:14376-14382

126. Hardie RC, Raghu P, Moore S, Juusola M, Baines A, Sweeney ST (2001) Calcium influx via TRP channels is required to maintain $\mathrm{PIP}_{2}$ levels in Drosophila photoreceptors. Neuron 30:149-159

127. Gu Y, Oberwinkler J, Postma M, Hardie RC (2005) Mechanisms of light adaptation in Drosophila photoreceptors. Curr Biol 15:1228-1234

128. Huang FD, Matthies HJ, Speese SD, Smith MA, Broadie K (2004) Rolling blackout, a newly identified PIP $_{2}$-DAG pathway lipase required for Drosophila phototransduction. Nat Neurosci 7:1070-1078

129. Masai I, Suzuki E, Yoon CS, Kohyama A, Hotta Y (1997) Immunolocalization of Drosophila eye-specific diacylgylcerol kinase, $r d g A$, which is essential for the maintenance of the photoreceptor. J Neurobiol 32:695-706

130. Suzuki E, Hirosawa K (1994) Immunolocalization of a Drosophila phosphatidylinositol transfer protein $(\mathrm{rdgB})$ in normal and $r d g A$ mutant photoreceptor cells with special reference to the subrhabdomeric cisternae. J Electron Microsc 43:183-189

131. Wang T, Montell C (2006) A phosphoinositide synthase required for a sustained light response. J Neurosci 26:12816-12825

132. Wu L, Niemeyer B, Colley N, Socolich M, Zuker CS (1995) Regulation of PLC-mediated signalling in vivo by CDPdiacylglycerol synthase. Nature 373:216-222

133. Inoue H, Yoshioka T, Hotta Y (1989) Diacylglycerol kinase defect in a Drosophila retinal degeneration mutant $r d g A$. J Biol Chem 264:5996-6000

134. Milligan SC, Alb JG Jr, Elagina RB, Bankaitis VA, Hyde DR (1997) The phosphatidylinositol transfer protein domain of Drosophila Retinal degeneration B protein is essential for photoreceptor cell survival and recovery from light stimulation. J Cell Biol 139:351-363

135. Vihtelic TS, Hyde DR, O'Tousa JE (1991) Isolation and characterization of the Drosophila retinal degeneration $B(\mathrm{rdg} B)$ gene. Genetics 127:761-768

136. Raghu P, Usher K, Jonas S, Chyb S, Polyanovsky A, Hardie RC (2000) Constitutive activity of the light-sensitive channels TRP and TRPL in the Drosophila diacylglycerol kinase mutant, $r d g A$. Neuron 26:169-179

137. LaLonde MM, Janssens H, Rosenbaum E, Choi SY, Gergen JP, Colley NJ, Stark WS, Frohman MA (2005) Regulation of phototransduction responsiveness and retinal degeneration by a phospholipase D-generated signaling lipid. J Cell Biol 169:471-479

138. Montell C, Jones K, Hafen E, Rubin G (1985) Rescue of the Drosophila phototransduction mutation trp by germline transformation. Science 230:1040-1043

139. Cosens DJ, Manning A (1969) Abnormal electroretinogram from a Drosophila mutant. Nature 224:285-287

140. Leung HT, Geng C, Pak WL (2000) Phenotypes of trpl mutants and interactions between the transient receptor potential (TRP) and TRP-like channels in Drosophila. J Neurosci 20:6797-6803

141. Reuss H, Mojet MH, Chyb S, Hardie RC (1997) In vivo analysis of the Drosophila light-sensitive channels, TRP and TRPL. Neuron 19:1249-1259

142. Xu XZ, Li HS, Guggino WB, Montell C (1997) Coassembly of TRP and TRPL produces a distinct store-operated conductance. Cell 89:1155-1164

143. Xu XZ, Chien F, Butler A, Salkoff L, Montell C (2000) TRP $\gamma$, a Drosophila TRP-related subunit, forms a regulated cation channel with TRPL. Neuron 26:647-657
144. Hardie RC (1995) Photolysis of caged $\mathrm{Ca}^{2+}$ facilitates and inactivates but does not directly excite light-sensitive channels in Drosophila photoreceptors. J Neurosci 15:889-902

145. Acharya JK, Jalink K, Hardy RW, Hartenstein V, Zuker CS (1997) $\mathrm{InsP}_{3}$ receptor essential for growth and differentiation but not for vision in Drosophila. Neuron 18:881-887

146. Raghu P, Colley NJ, Webel R, James T, Hasan G, Danin M, Selinger Z, Hardie RC (2000) Normal phototransduction in Drosophila photoreceptors lacking an $\mathrm{InsP}_{3}$ receptor gene. Mol Cell Neurosci 15:429-445

147. Hardie RC, Raghu P (1998) Activation of heterologously expressed Drosophila TRPL channels: $\mathrm{Ca}^{2+}$ is not required and $\mathrm{InsP}_{3}$ is not sufficient. Cell Calcium 24:153-163

148. Chyb S, Raghu P, Hardie RC (1999) Polyunsaturated fatty acids activate the Drosophila light-sensitive channels TRP and TRPL. Nature 397:255-259

149. Li C, Geng C, Leung HT, Hong YS, Strong LL, Schneuwly S, Pak WL (1999) INAF, a protein required for transient receptor potential $\mathrm{Ca}^{2+}$ channel function. Proc Natl Acad Sci USA 96:13474-13479

150. Wang T, Jiao Y, Montell C (2005) Dissecting independent channel and scaffolding roles of the Drosophila transient receptor potential channel. J Cell Biol 171:685-694

151. Oberwinkler J, Stavenga DG (2000) Calcium transients in the rhabdomeres of dark- and light-adapted fly photoreceptor cells. J Neurosci 20:1701-1709

152. Oberwinkler J, Stavenga DG (1998) Light dependence of calcium and membrane potential measured in blowfly photoreceptors in vivo. J Gen Physiol 112:113-124

153. Hardie RC (1996) INDO-1 measurements of absolute resting and light-induced $\mathrm{Ca}^{2+}$ concentration in Drosophila photoreceptors. J Neurosci 16:2924-2933

154. Ruknudin A, Valdivia C, Kofuji P, Lederer WJ, Schulze DH (1997) $\mathrm{Na}^{+} / \mathrm{Ca}^{2+}$ exchanger in Drosophila: cloning, expression, and transport differences. Am J Physiol 273:C257-C265

155. Schwarz EM, Benzer S (1997) Calx, a Na-Ca exchanger gene of Drosophila melanogaster. Proc Natl Acad Sci USA 94:10249 10254

156. Hryshko LV, Matsuoka S, Nicoll DA, Weiss JN, Schwarz EM, Benzer S, Philipson KD (1996) Anomalous regulation of the Drosophila $\mathrm{Na}^{+}-\mathrm{Ca}^{2+}$ exchanger by $\mathrm{Ca}^{2+}$. J Gen Physiol 108:67-74

157. Wang T, Xu H, Oberwinkler J, Gu Y, Hardie RC, Montell C (2005) Light activation, adaptation, and cell survival functions of the $\mathrm{Na}^{+} / \mathrm{Ca}^{2+}$ exchanger CalX. Neuron 45:367-378

158. Haab JE, Vergara C, Bacigalupo J, O’Day PM (2000) Coordinated gating of TRP-dependent channels in rhabdomeral membranes from Drosophila retinas. J Neurosci 20:7193-7198

159. Scott K, Sun Y, Beckingham K, Zuker CS (1997) Calmodulin regulation of Drosophila light-activated channels and receptor function mediates termination of the light response in vivo. Cell 91:375-383

160. Ranganathan R, Bacskai BJ, Tsein RY, Zuker CS (1994) Cytosolic calcium transients: spatial localization and role in Drosophila photoreceptor cell function. Neuron 13:837-848

161. Hardie RC, Minke B (1994) Calcium-dependent inactivation of light-sensitive channels in Drosophila photoreceptors. J Gen Physiol 103:409-427

162. Schaeffer E, Smith D, Mardon G, Quinn W, Zuker C (1989) Isolation and characterization of two new Drosophila protein kinase $\mathrm{C}$ genes, including one specifically expressed in photoreceptor cells. Cell 57:403-412

163. Smith DP, Ranganathan R, Hardy RW, Marx J, Tsuchida T, Zuker CS (1991) Photoreceptor deactivation and retinal degeneration mediated by a photoreceptor-specific protein kinase C. Science 254:1478-1484

164. Huber A, Sander P, Bähner M, Paulsen R (1998) The TRP $\mathrm{Ca}^{2+}$ channel assembled in a signaling complex by the PDZ domain 
protein INAD is phosphorylated through the interaction with protein kinase C (ePKC). FEBS Lett 425:317-322

165. Liu M, Parker LL, Wadzinski BE, Shieh BH (2000) Reversible phosphorylation of the signal transduction complex in Drosophila photoreceptors. J Biol Chem 275:12194-12199

166. Popescu DC, Ham AJ, Shieh BH (2006) Scaffolding protein INAD regulates deactivation of vision by promoting phosphorylation of transient receptor potential by eye protein kinase $\mathrm{C}$ in Drosophila. J Neurosci 26:8570-8577

167. Li HS, Porter JA, Montell C (1998) Requirement for the NINAC kinase/myosin for stable termination of the visual cascade. J Neurosci 18:9601-9606

168. Porter JA, Yu M, Doberstein SK, Pollard TS, Montell C (1993) Dependence of calmodulin localization in the retina on the ninaC unconventional myosin. Science 262:1038-1042

169. Porter JA, Minke B, Montell C (1995) Calmodulin binding to Drosophila NinaC required for termination of phototransduction. EMBO J 18:4450-4459

170. Yamanaka MK, Saugstad JA, Hanson-Painton O, McCarthy BJ, Tobin SL (1987) Structure and expression of the Drosophila calmodulin gene. Nucl Acids Res 15:3335-3348

171. Doyle KE, Kovalick GE, Lee E, Beckingham K (1990) Drosophila melanogaster contains a single calmodulin gene. Further structure and expression studies. J Mol Biol 213:599-605

172. Heiman RG, Atkinson RC, Andruss BF, Bolduc C, Kovalick GE, Beckingham K (1996) Spontaneous avoidance behavior in Drosophila null for calmodulin expression. Proc Natl Acad Sci USA 93:2420-2425

173. Chevesich J, Kreuz AJ, Montell C (1997) Requirement for the PDZ domain protein, INAD, for localization of the TRP storeoperated channel to a signaling complex. Neuron 18:95-105

174. Warr CG, Kelly LE (1996) Identification and characterization of two distinct calmodulin-binding sites in the Trpl ionchannel protein of Drosophila melanogaster. Biochem J 314: 497-503

175. Han J, Gong P, Reddig K, Mitra M, Guo P, Li HS (2006) The fly CAMTA transcription factor potentiates deactivation of rhodopsin, a G protein-coupled light receptor. Cell 127:847-858

176. Ho MS, Tsai PI, Chien CT (2006) F-box proteins: the key to protein degradation. J Biomed Sci 13:181-191

177. Wojcikiewicz RJ (2004) Regulated ubiquitination of proteins in GPCR-initiated signaling pathways. Trends Pharmacol Sci 25:35-41

178. Whelan JP, McGinnis JF (1988) Light-dependent subcellular movement of photoreceptor proteins. J Neurosci Res 20:263-270

179. Philp NJ, Chang W, Long K (1987) Light-stimulated protein movement in rod photoreceptor cells of the rat retina. FEBS Lett. 225:127-132

180. Mangini NJ, Pepperberg DR (1988) Immunolocalization of $48 \mathrm{~K}$ in rod photoreceptors. Light and ATP increase OS labeling. Invest Ophthalmol Vis Sci 29:1221-1234

181. Broekhuyse RM, Tolhuizen EF, Janssen AP, Winkens HJ (1985) Light induced shift and binding of S-antigen in retinal rods. Curr Eye Res 4:613-618

182. Lee SJ, Xu H, Kang LW, Amzel LM, Montell C (2003) Light adaptation through phosphoinositide-regulated translocation of Drosophila visual arrestin. Neuron 39:121-132

183. Cronin MA, Diao F, Tsunoda S (2004) Light-dependent subcellular translocation of $\mathrm{G}_{\mathrm{q} \alpha}$ in Drosophila photoreceptors is facilitated by the photoreceptor-specific myosin III NINAC. J Cell Sci 117:4797-4806

184. Calvert PD, Strissel KJ, Schiesser WE, Pugh EN Jr, Arshavsky VY (2006) Light-driven translocation of signaling proteins in vertebrate photoreceptors. Trends Cell Biol 16:560-568

185. Bähner M, Frechter S, Da Silva N, Minke B, Paulsen R, Huber A (2002) Light-regulated subcellular translocation of Drosophila
TRPL channels induces long-term adaptation and modifies the light-induced current. Neuron 34:83-93

186. Cronin MA, Lieu MH, Tsunoda S (2006) Two stages of lightdependent TRPL-channel translocation in Drosophila photoreceptors. J Cell Sci 119:2935-2944

187. Yoon J, Ben-Ami HC, Hong YS, Park S, Strong LL, Bowman J, Geng C, Baek K, Minke B, Pak WL (2000) Novel mechanism of massive photoreceptor degeneration caused by mutations in the trp gene of Drosophila. J Neurosci 20:649-659

188. Meyer NE, Joel-Almagor T, Frechter S, Minke B, Huber A (2006) Subcellular translocation of the eGFP-tagged TRPL channel in Drosophila photoreceptors requires activation of the phototransduction cascade. J Cell Sci 119:2592-2603

189. Lee SJ, Montell C (2004) Light-dependent translocation of visual arrestin regulated by the NINAC myosin III. Neuron 43:95-103

190. Komaba S, Inoue A, Maruta S, Hosoya H, Ikebe M (2003) Determination of human myosin III as a motor protein having a protein kinase activity. J Biol Chem 278:21352-21360

191. Kambara T, Komaba S, Ikebe M (2006) Human myosin III is a motor having an extremely high affinity for actin. J Biol Chem 281:37291-37301

192. Dosé AC, Ananthanarayanan S, Moore JE, Burnside B, Yengo CM (2007) Kinetic mechanism of human myosin IIIA. J Biol Chem 282:216-231

193. Arikawa K, Hicks JL, Williams DS (1990) Identification of actin filaments in the rhabdomeral microvilli of Drosophila photoreceptors. J Cell Biol 110:1993-1998

194. Porter JA, Hicks JL, Williams DS, Montell C (1992) Differential localizations of and requirements for the two Drosophila ninaC kinase/myosins in photoreceptor cells. J Cell Biol 116:683-693

195. Li HS, Montell C (2000) TRP and the PDZ protein, INAD, form the core complex required for retention of the signalplex in Drosophila photoreceptor cells. J Cell Biol 150:1411-1422

196. Huber A, Sander P, Gobert A, Bähner M, Hermann R, Paulsen R (1996) The transient receptor potential protein (Trp), a putative store-operated $\mathrm{Ca}^{2+}$ channel essential for phosphoinositidemediated photoreception, forms a signaling complex with NorpA, InaC and InaD. EMBO J 15:7036-7045

197. Shieh B-H, Zhu M-Y (1996) Regulation of the TRP Ca ${ }^{2+}$ channel by INAD in Drosophila photoreceptors. Neuron 16:991-998

198. Tsunoda S, Sierralta J, Sun Y, Bodner R, Suzuki E, Becker A, Socolich M, Zuker CS (1997) A multivalent PDZ-domain protein assembles signalling complexes in a G-protein-coupled cascade. Nature 388:243-249

199. Tsunoda S, Sun Y, Suzuki E, Zuker C (2001) Independent anchoring and assembly mechanisms of INAD signaling complexes in Drosophila photoreceptors. J Neurosci 21:150-158

200. Xu XZ, Choudhury A, Li X, Montell C (1998) Coordination of an array of signaling proteins through homo- and heteromeric interactions between PDZ domains and target proteins. J Cell Biol 142:545-555

201. Wes PD, Xu X-ZS, Li H-S, Chien F, Doberstein SK, Montell C (1999) Termination of phototransduction requires binding of the NINAC myosin III and the PDZ protein INAD. Nat Neurosci 2:447-453

202. Goel M, Garcia R, Estacion M, Schilling WP (2001) Regulation of Drosophila TRPL channels by immunophilin FKBP59. J Biol Chem 276:38762-38773

203. Adamski FM, Zhu M-Y, Bahiraei F, Shieh B-H (1998) Interaction of eye protein kinase $\mathrm{C}$ and INAD in Drosophila: localization of binding domains and electrophysiological characterization of a loss of association in transgenic flies. J Biol Chem 273:17713-17719

204. Schechtman D, Mochly-Rosen D (2001) Adaptor proteins in protein kinase $\mathrm{C}$-mediated signal transduction. Oncogene 20:6339-6347 
205. Smith FD, Langeberg LK, Scott JD (2006) The where's and when's of kinase anchoring. Trends Biochem Sci 31:316-323

206. Shieh B-H, Niemeyer B (1995) A novel protein encoded by the InaD gene regulates recovery of visual transduction in Drosophila. Neuron 14:201-210

207. Washburn T, O'Tousa JE (1989) Molecular defects in Drosophila rhodopsin mutants. J Biol Chem 264:15464-15466

208. O'Tousa JE, Leonard DS, Pak WL (1989) Morphological defects in ora $^{J K 84}$ photoreceptors caused by mutation in R1-R6 opsin gene in Drosophila. J Neurogenet 6:41-52

209. Dryja TP, Hahn LB, Cowley GS, McGee TL, Berson EL (1991) Mutation spectrum of the rhodopsin gene among patients with autosomal dominant retinitis pigmentosa. Proc Natl Acad Sci USA 88:9370-9374

210. Sung CH, Davenport CM, Nathans J (1993) Rhodopsin mutations responsible for autosomal dominant retinitis pigmentosa. Clustering of functional classes along the polypeptide chain. J Biol Chem 268:26645-26649

211. Nathans J, Piantanida TP, Eddy RL, Shows TB, Hogness DS (1986) Molecular genetics of inherited variation in human color vision. Science 232:203-210

212. Nathans J, Hogness DS (1984) Isolation and nucleotide sequence of the gene encoding human rhodopsin. Proc Natl Acad Sci USA $81: 4851-4855$

213. Dryja TP, McGee TL, Reichel E, Hahn LB, Cowley GS, Yandell DW, Sandberg MA, Berson EL (1990) A point mutation of the rhodopsin gene in one form of retinitis pigmentosa. Nature 343:364-366

214. Kumar JP, Ready DF (1995) Rhodopsin plays an essential structural role in Drosophila photoreceptor development. Development 121:4359-4570

215. Leonard DS, Bowman VD, Ready DF, Pak WL (1992) Degeneration of photoreceptors in rhodopsin mutants of Drosophila. J Neurobiol 23:605-626

216. Colley NJ, Cassill JA, Baker EK, Zuker CS (1995) Defective intracellular transport is the molecular basis of rhodopsindependent dominant retinal degeneration. Proc Natl Acad Sci USA 92:3070-3074

217. Kurada P, O'Tousa JE (1995) Retinal degeneration caused by dominant rhodopsin mutations in Drosophila. Neuron 14:571-579

218. Pacione LR, Szego MJ, Ikeda S, Nishina PM, McInnes RR (2003) Progress toward understanding the genetic and biochemical mechanisms of inherited photoreceptor degenerations. Annu Rev Neurosci 26:657-700

219. Kurada P, Tonini TD, Serikaku MA, Piccini JP, O'Tousa JE (1998) Rhodopsin maturation antagonized by dominant rhodopsin mutants. Vis Neurosci 15:693-700

220. Johnson EC, Pak WL (1986) Electrophysiological study of Drosophila rhodopsin mutants. J Gen Physiol 88:651-673

221. Galy A, Roux MJ, Sahel JA, Leveillard T, Giangrande A (2005) Rhodopsin maturation defects induce photoreceptor death by apoptosis: a fly model for Rhodopsin ${ }^{\text {Pro23His }}$ human retinitis pigmentosa. Hum Mol Genet 14:2547-2557

222. Iakhine R, Chorna-Ornan I, Zars T, Elia N, Cheng Y, Selinger Z, Minke B, Hyde DR (2004) Novel dominant rhodopsin mutation triggers two mechanisms of retinal degeneration and photoreceptor desensitization. J Neurosci 24:2516-2526

223. Orem NR, Xia L, Dolph PJ (2006) An essential role for endocytosis of rhodopsin through interaction of visual arrestin with the AP-2 adaptor. J Cell Sci 119:3141-3148

224. Acharya U, Mowen MB, Nagashima K, Acharya JK (2004) Ceramidase expression facilitates membrane turnover and endo- cytosis of rhodopsin in photoreceptors. Proc Natl Acad Sci USA 101:1922-1926

225. Acharya U, Patel S, Koundakjian E, Nagashima K, Han X, Acharya JK (2003) Modulating sphingolipid biosynthetic pathway rescues photoreceptor degeneration. Science 299:1740-1743

226. Orrenius S, Zhivotovsky B, Nicotera P (2003) Regulation of cell death: the calcium-apoptosis link. Nat Rev Mol Cell Biol 4:552-565

227. Masai I, Okazaki A, Hosoya T, Hotta Y (1993) Drosophila retinal degeneration A gene encodes an eye-specific diacylglycerol kinase with cysteine-rich zinc-finger motifs and ankyrin repeats. Proc Natl Acad Sci USA 90:11157-11161

228. Georgiev P, Garcia-Murillas I, Ulahannan D, Hardie RC, Raghu P (2005) Functional INAD complexes are required to mediate degeneration in photoreceptors of the Drosophila $r d g A$ mutant. J Cell Sci 118:1373-1384

229. Vihtelic TS, Goebl M, Milligan S, O’Tousa JE, Hyde DR (1993) Localization of Drosophila retinal degeneration $B$, a membraneassociated phosphatidylinositol transfer protein. J Cell Biol 122:1013-1022

230. Paetkau DW, Elagin VA, Sendi LM, Hyde DR (1999) Isolation and characterization of Drosophila retinal degeneration $B$ suppressors. Genetics 151:713-724

231. Sahly I, Bar Nachum S, Suss-Toby E, Rom A, Peretz A, Kleiman J, Byk T, Selinger Z, Minke B (1992) Calcium channel blockers inhibit retinal degeneration in the retinal-degeneration-B mutant of Drosophila. Proc Natl Acad Sci USA 89:435-439

232. Jacobson SG, McInnes RR (2002) Blinded by the light. Nat Genet 32:215-216

233. Lee SJ, Montell C (2004) Suppression of constant-light-induced blindness but not retinal degeneration by inhibition of the rhodopsin degradation pathway. Curr Biol 14:2076-2085

234. Davidson FF, Steller H (1998) Blocking apoptosis prevents blindness in Drosophila retinal degeneration mutants. Nature 391:587-591

235. Hsu CD, Whaley MA, Frazer K, Miller DA, Mitchell KA, Adams SM, O'Tousa JE (2004) Limited role of developmental programmed cell death pathways in Drosophila norpA retinal degeneration. J Neurosci 24:500-507

236. Chuang JZ, Vega C, Jun W, Sung CH (2004) Structural and functional impairment of endocytic pathways by retinitis pigmentosa mutant rhodopsin-arrestin complexes. J Clin Invest 114:131-140

237. Chen J, Shi G, Concepcion FA, Xie G, Oprian D, Chen J (2006) Stable rhodopsin/arrestin complex leads to retinal degeneration in a transgenic mouse model of autosomal dominant retinitis pigmentosa. J Neurosci 26:11929-11937

238. den Hollander AI, ten Brink JB, de Kok YJ, van Soest S, van den Born LI, van Driel MA, van de Pol DJ, Payne AM, Bhattacharya SS, Kellner U, Hoyng CB, Westerveld A, Brunner HG, Bleeker-Wagemakers EM, Deutman AF, Heckenlively JR, Cremers FP, Bergen AA (1999) Mutations in a human homologue of Drosophila crumbs cause retinitis pigmentosa (RP12). Nat Genet 23:217-221

239. Johnson K, Grawe F, Grzeschik N, Knust E (2002) Drosophila Crumbs is required to inhibit light-induced photoreceptor degeneration. Curr Biol 12:1675-1680

240. Hassan BA, Prokopenko SN, Breuer S, Zhang B, Paululat A, Bellen HJ (1998) Skittles, a Drosophila phosphatidylinositol 4phosphate 5-kinase, is required for cell viability, germline development and bristle morphology, but not for neurotransmitter release. Genetics 150:1527-1537

241. Montell C (2005) The TRP superfamily of cation channels. Sci STKE 2005:re3 